\section{A) Check for updates}

Cite this: Org. Chem. Front., 2021, 8 6561

Received 25th August 2021 Accepted 1st October 2021

DOI: 10.1039/d1qo01276b

rsc.li/frontiers-organic

\title{
Homolysis/mesolysis of alkoxyamines activated by chemical oxidation and photochemical-triggered radical reactions at room temperature $\uparrow$
}

\author{
Gérard Audran, ${ }^{\star a}$ Mitchell T. Blyth, (DD ${ }^{b}$ Michelle L. Coote, (D) ${ }^{b}$ Georg Gescheidt, (DD ${ }^{c}$

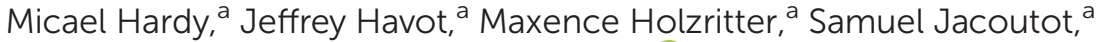 \\ Jean-Patrick Joly, ${ }^{\text {a }}$ Sylvain R. A. Marque, iD *a \\ Tataye Moussounda Moussounda Koumba, ${ }^{a}$ Dmytro Neshchadin (iD ${ }^{c}$ and \\ Enzo Vaiedelich ${ }^{a}$
}

\begin{abstract}
Alkoxyamines, which are connected with a phenol moiety by a (substituted) methylene bridge undergo homolytic cleavage upon chemical oxidation or a photo-induced hydrogen transfer. This selectively triggered reaction yields a nitroxide radical. In the presence of an excess of lead dioxide as the oxidant in tert-butylbenzene as solvent, spontaneous, instantaneous and almost quantitative generations of nitroxides from various alkoxyamines are observed at room temperature, which support activation energies for the cleavage lower than $100 \mathrm{~kJ} \mathrm{~mol}^{-1}$. The rate and the amount of released nitroxide depend on the amount of "catalyst" and the structure of alkoxyamines.
\end{abstract}

\section{Introduction}

In the last decade, the concept of smart alkoxyamines has been developed. ${ }^{1}$ These are highly stable alkoxyamines with half-lives of several hundred years, which can be selectively transformed into highly labile species with half-lives of seconds or minutes through chemical, ${ }^{2-5}$ photochemical $^{6-9}$ or biochemical $^{10,11}$ events. Such alkoxyamines have interesting properties for potential applications in industry, e.g., safe storage of initiators for radical polymerizations, ${ }^{5,12}$ or in biology, e.g., drugs for cancer or parasites. ${ }^{10,11,13-18}$

While the focus of these studies has been on triggering alkoxyamine homolysis, to form a nitroxide and carbon-centred radical, recently it has been shown that upon oxidation, through electrochemical ${ }^{19-23}$ or photoredox ${ }^{24,25}$ methods, alkoxyamines can spontaneously undergo mesolytic cleavage instead. Depending on the leaving group and other species present, this process can yield nitroxides and carbocations, or

\footnotetext{
${ }^{a}$ Aix Marseille Univ, CNRS, ICR, UMR 7273, Case 551,

Avenue Escadrille Normandie-Niemen, 13397 Marseille Cedex 20, France. E-mail:sylvain.marque@univ-amu.fr, g.audran@univ-amU.fr, jp.joly@live.fr

${ }^{b}$ Research School of Chemistry, Australian National University, Canberra, ACT 2601, Australia

${ }^{c}$ Institute of Physical and Theoretical Chemistry, TU Graz, Stremayrgasse 9/Z2, A-8010 Graz, Austria

$\dagger$ Electronic supplementary information (ESI) available: HRMS and NMR spectra of $\mathbf{1 a}, \mathbf{b}-\mathbf{5 a}, \mathbf{b}, \mathbf{3 d}$ and $\mathbf{3 e}, \mathrm{p} K_{\mathrm{a}}$ determination of 4 -vinylphenol, HPLC-ESI analysis of 3a and 3e in THF, and DFT calculations. See DOI: 10.1039/d1q001276b
}

alternatively oxoamoniums and carbon-centred radicals. In some cases, oxidation simply generates reactive intermediates capable of undergoing $\mathrm{S}_{\mathrm{N}} 2$ reactions with nucleophiles. These processes have been developed into successful alkylation methods in small molecule synthesis, ${ }^{21,24}$ and likely have broader applications for the on-demand generation of carbon-centred radicals and cations. Moreover, it is thought that this mesolytic cleavage pathway may even be operative upon photochemical excitation of certain photoactive alkoxyamines. $^{26}$

To date, oxidative alkoxyamine cleavage has been achieved using either electrochemical ${ }^{19-23}$ or photoredox $^{24}$ methods, but the use of simple chemical oxidation under mild conditions has not yet been reported. Indeed, while $\mathrm{PbO}_{2}$ has been shown to generate phenoxyl radicals from phenol-based anti-oxidants through proton-coupled electron transfer $(\mathrm{PCET}),{ }^{27}$ preliminary results with $3 \mathrm{c}$ show only very low conversion into nitroxide $3^{\cdot}$ using $\mathrm{PbO}_{2}$ as oxidant. Here, we report on the preparation phenol-based alkoxyamines 1a5a,3e (Chart 1) and the benzyl protected homologues $\mathbf{1 b}$ 5b,3d (Chart 1). We have investigated their reaction pathways in $t$ - $\mathrm{BuPh}$ as the solvent. At room temperature 1a-5a reacted with $\mathrm{PbO}_{2}$ affording almost quantitative conversions to the corresponding nitroxides. Kinetic investigations by EPR, product analysis, NMR/CIDNP, and DFT calculations of $1 \mathbf{a}-\mathbf{5 a}$ are used to unveil the pathways leading both to the decay of alkoxyamines and to the generation of nitroxides. 

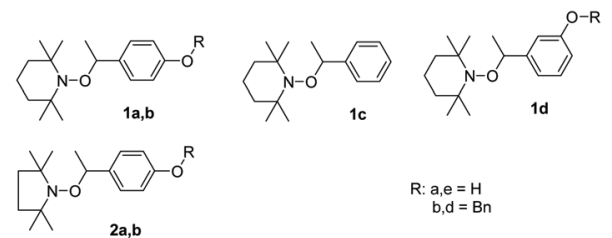

$\begin{aligned} R: a, e & =H \\ b, d & =B n\end{aligned}$
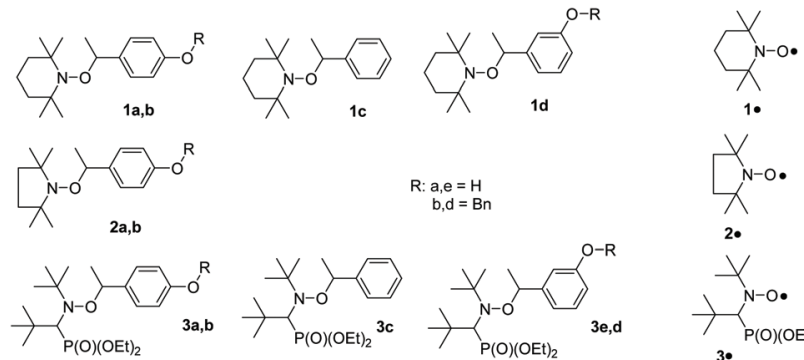

2•

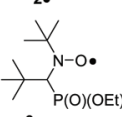

3.
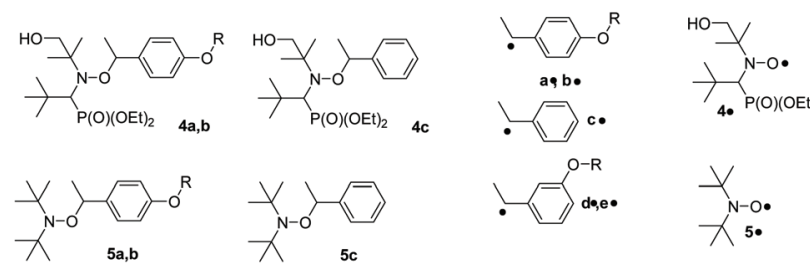

Chart 1 Alkoxyamines and nitroxides investigated.

\section{Results}

\section{Synthesis}

para-Vinyl phenol is protected by benzylation, ${ }^{28}+$ to afford $\mathbf{6}$, which is coupled with nitroxides $\mathbf{1}^{\circ}-\mathbf{5}^{\circ}$ using the $\mathrm{Mn}$ (salen) method to yield $\mathbf{1} \mathbf{b}-\mathbf{5} \mathbf{b} .{ }^{29} \S$ Then, $\mathbf{1 b}-\mathbf{5} \mathbf{b}$ are deprotected using $\mathrm{H}_{2}$ and the catalyst $\mathrm{Pd} / \mathrm{C}^{28}$ to yield 1a-5a (Scheme 1).

The same procedures as displayed in Scheme 1 are applied for the preparation of $\mathbf{1 d}, \mathbf{3 d}$, and 3e starting from meta-vinylphenol in $25 \%, 55 \%$, and $74 \%$ yields, respectively.

\section{Thermal homolysis}

Effects of various substituents attached to the nitroxyl moiety on the homolysis rate constant $k_{\mathrm{d}}$ of the C-ON bond in alkoxyamines (Scheme 2) have been thoroughly investigated ${ }^{30-33}$ and it was shown that steric, polar and stabilization effects are strongly entangled. ${ }^{34,35}$ Noteworthy, for the thermal C-ON bond homolysis, differences of $E_{\mathrm{a}}$ of $c a .5-7 \mathrm{~kJ} \mathrm{~mol}^{-1}$ between 1a and 3a, of $c a$. 5-7 kJ mol ${ }^{-1}$ between $3 \mathbf{a}$ and $4 \mathbf{a}$, of $c a$. 2-4 kJ $\mathrm{mol}^{-1}$ between $3 \mathbf{a}$ and $\mathbf{5 a}$ are in the range of differences observed for analogue alkoxyamines. It means that the $\mathrm{C}-\mathrm{ON}$ bond homolysis of 1a, 3a-5a is ruled by the polarity and bulkiness of the nitroxyl fragment, and stabilization of the released nitroxide as previously reported. ${ }^{34}$ Therefore, the thermal-triggered homolysis of 1a-5a occurs via the established mechanism $^{34}$ displayed in Scheme 2. Importantly, at high temperatures, in the presence of $\mathrm{O}_{2}$, the generation of alkyl radicals, peroxyl radicals, alkoxyl radicals and nitroxides do not alter the kinetics. Hence, the mechanism of homolysis via a selfcatalytic event in which the phenoxyl moiety would play the

$\$$ Disappointingly, all attempts for the preparation of $\mathbf{1 a}, \mathbf{2 a}$, and $5 \mathbf{a}$ using the procedure described in $\S$ failed.

$\S$ Alkoxyamines $3 \mathbf{a}$ and $\mathbf{4 a}$ are also prepared by the coupling of nitroxides $3^{\circ}$ and $4^{*}$ with the commercially available para-vinyl phenol using the procedure $\mathrm{Mn}$ (salen) (Scheme 1a).

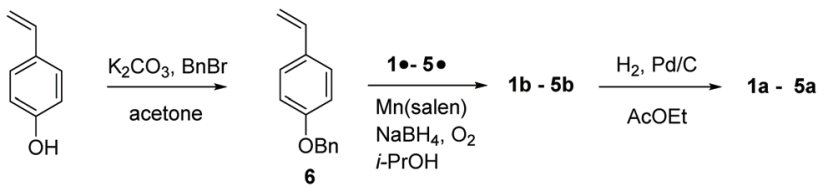

Scheme 1 Preparation of $1 a-5 a$.

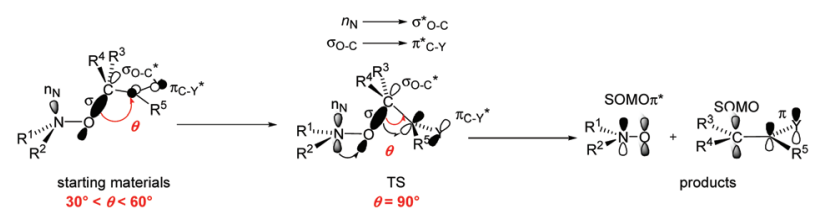

Scheme 2 Geometrical parameters and orbital interactions expected in starting materials, TS, and products during the homolysis event.

role of radical scavenger, analogous to the Denisov cycle ${ }^{36}$ is highly unlikely.

Effects of para-aryl substituent for $\mathbf{1}^{-37}$ and 3 -based ${ }^{38}$ alkoxyamines have been thoroughly investigated and linear free energy relationships (LFER) were observed for 1-based alkoxyamines ${ }^{37}$ with the Hammett constant $\sigma_{\mathrm{p}}$ (ref. 39) and for 3-based alkoxyamines ${ }^{38}$ with localized polar effect for parasubstituted phenyl groups $\sigma_{\mathrm{L}, 4-\mathrm{x}-\mathrm{C}_{6} \mathrm{H}_{4}}{ }^{40,41}$ Thus, $E_{\mathrm{a}}$ of $134.3 \mathrm{~kJ}$ $\mathrm{mol}^{-1} \boldsymbol{q}$ and $126.2 \mathrm{~kJ} \mathrm{~mol}^{-1} \|$ are estimated for 1a and 3a, respectively, in nice agreement with the experimental values reported in Table 1. Moreover, very similar values of $E_{\mathrm{a}}$ are expected for $\mathbf{1 a}$ and $\mathbf{1} \mathbf{b}^{* *}$ as well as for $\mathbf{3 a}$ and $\mathbf{3} \mathbf{b} \dagger \dagger$ agreeing with the values reported in Table 1 . The trends in $E_{\mathrm{a}}$ observed for $\mathbf{1 a}-\mathbf{5 a}$ are also observed for $\mathbf{1 b}-\mathbf{5 b}$. Hence, the C-ON bond homolysis for $\mathbf{1} \mathbf{a}, \mathbf{b}-\mathbf{5} \mathbf{a}, \mathbf{b}$ occur through TS exhibiting the same features: ${ }^{34}$ flattening at the $\mathrm{N}$ - and C-atoms of the C-ON moiety, rotation around the $\mathrm{N}-\mathrm{O}$ bond to reach the dihedral angle $\langle$ nitrogen lone pair NOC $\rangle$ at $0^{\circ} \mathrm{H}$ and rotation around the C-aryl bond to reach the dihedral angle $\langle$ OCaryl $\rangle$ at $90^{\circ}$. These geometric requirements favour the donating interactions $\mathrm{n}_{\mathrm{N}} \rightarrow \sigma^{*}{ }_{\mathrm{O}-\mathrm{C}}$ of the nitrogen lone pair $\mathrm{n}_{\mathrm{N}}$ into the $\mathrm{C}-\mathrm{O}$ antibonding orbital $\sigma^{*}{ }_{\mathrm{O}-\mathrm{C}}$, which in turn favours the donating interaction $\sigma_{\mathrm{O}-\mathrm{C}} \rightarrow \pi^{*}$ aryl of the $\mathrm{O}-\mathrm{C}$ bonding orbital $\sigma_{\mathrm{O}-\mathrm{C}}$ into the antibonding orbital $\pi^{*}$ of the aryl moiety (Scheme 2).

\section{Chemical oxidation}

Taking into account the half-life times of $\mathbf{1 a}-\mathbf{5 a}$ at $25{ }^{\circ} \mathrm{C}\left(t_{1 / 2}=\right.$ 24 days for $\mathbf{4 a}$ is the shortest, Table 1), these alkoxyamines are considered as stable during the 60 seconds of experimental time, i.e., thermal homolysis of $0.1 \mathrm{mM}$ of $4 \mathrm{a}$ affords $0.7 \mathrm{nM}$ of

$\left\lceil\sigma_{\mathrm{p}, \mathrm{OH}}=-0.37\right.$, see ref. 39 , and equation in Fig. 2 in ref. 37.

$\| \sigma_{\mathrm{L}, \mathrm{OH}}=0.24$ and $\sigma_{\mathrm{R}, \mathrm{OH}}^{0}=-049$, see ref. 40 , and eqn (1) and (5a) in ref. 38 .

${ }^{*}$ It was assumed that $\sigma_{\mathrm{p}, \mathrm{OCH}_{2} \mathrm{Ph}} \approx \sigma_{\mathrm{p}, \mathrm{OEt}}=-0.32$, see ref. 39 , and equation in Fig. 2 in ref. 37 .

$\dagger \dagger$ It was assumed that $\sigma_{\mathrm{L}, 4-\mathrm{BnOC}_{6} \mathrm{H}_{4}} \approx \sigma_{\mathrm{p}, \mathrm{OEt}}, \sigma_{\mathrm{L}, \mathrm{OEt}}=0.28$ and $\sigma_{\mathrm{R}, \mathrm{OEt}}^{0}=-044$, see ref. 40 , and eqn (1) and (5a) in ref. 38.

$\$$ In general, this angle exhibit a deviation less than $\pm 20^{\circ}$ meaning that a very low activation entropic cost is expected. 
Table 1 Homolysis rate constants $k_{\mathrm{d}}$ for alkoxyamines $(0.1 \mathrm{mM}) 1 \mathrm{a}, \mathrm{d}-5 \mathrm{a}, \mathrm{b}$, and $3 \mathrm{~d}$,e at various temperatures $T$ in tert-butylbenzene as solvent and their corresponding activation energies $E_{\mathrm{a}}$, homolysis rate constants $k_{\mathrm{d}}^{\prime}$ at $120{ }^{\circ} \mathrm{C}$ and half-life time $t_{1 / 2}$ at $25^{\circ} \mathrm{C}$

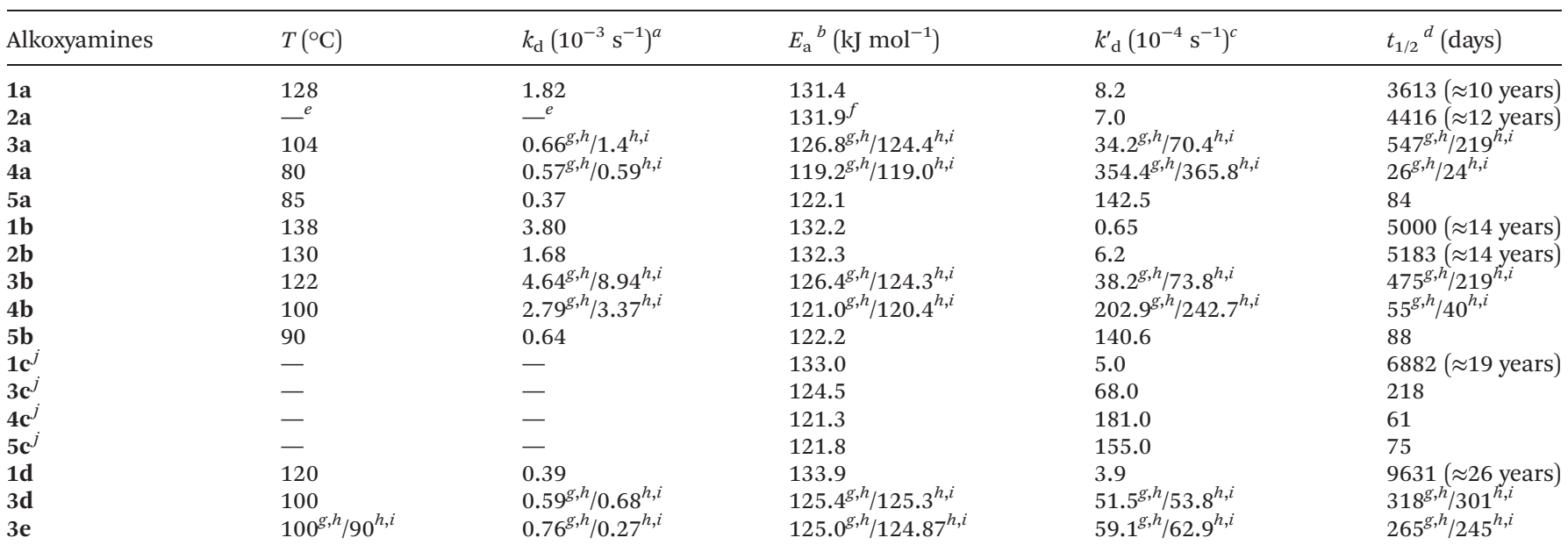

${ }^{a}$ Values determined by EPR and using eqn (2). ${ }^{b}$ Assuming an averaged frequency factor $A=2.4 \times 10^{14} \mathrm{~s}^{-1}$ (see ref. 34) and values of $T$ and $k$ given in second and third columns, respectively. ${ }^{c}$ Values estimated at $T=120^{\circ} \mathrm{C}$ assuming an averaged frequency factor $A=2.4 \times 10^{14} \mathrm{~S}^{-1}$ (see ref. 34 ) and values of $E_{\mathrm{a}}$ given in fourth columns. ${ }^{d}$ Given at $25{ }^{\circ} \mathrm{C}$ and using values of $k_{\mathrm{d}}$ estimated as described in footnote c. ${ }^{e}$ At $T=139{ }^{\circ} \mathrm{C}, k_{\mathrm{d}}=3.8$ $10^{-3} \mathrm{~s}^{-1}$ (eqn (2)), $E_{\mathrm{a}}=132.7 \mathrm{~kJ} \mathrm{~mol}^{-1}$ (see footnote b), and at $T=120{ }^{\circ} \mathrm{C}, k_{\mathrm{d}}=0.910^{-3} \mathrm{~s}^{-1}$ (eqn (2)), $E_{\mathrm{a}}=131.1 \mathrm{~kJ}$ mol ${ }^{-1}$ (see footnote b). ${ }^{f}$ Averaged values of $E_{\mathrm{a}}$ reported in footnote e. ${ }^{g}$ First fraction in chromatography. ${ }^{h}$ Relative configurations were not determined. ${ }^{i}$ Second fraction in chromatography. ${ }^{j}$ See ref. 34 .

nitroxide, below the threshold of detection of EPR at ca. $10 \mathrm{nM}$. $\mathrm{PbO}_{2}$ is currently used to oxidize phenolic anti-oxidant into their corresponding phenoxyl radical for their detection by EPR. ${ }^{42}$ Adding $\mathrm{PbO}_{2}$ to $0.1 \mathrm{mM}$ solution of $\mathbf{1 a - 5 a}$ at room temperature does not generate the EPR signal of the corresponding phenoxyl radical but an instantaneous raise of EPR signals corresponding to nitroxides $\mathbf{1}^{-}-\mathbf{5}^{\mathbf{*}}$. The intensity of the EPR signal of $\mathbf{1}^{-} \mathbf{5}^{\mathbf{}}$ is $\mathrm{PbO}_{2}$-concentration dependent affording bellshaped curves (Fig. 1). On the left-hand side of the top of bell curve, concentration in $\mathrm{PbO}_{2}$ is too low for complete oxidation§§ whereas on the right-hand side, concentration in $\mathrm{PbO}_{2}$ is too large that it reacts with nitroxides. Nitroxides $\mathbf{4}^{\circ}$ and $\mathbf{5}^{\circ}$ are not displayed in Fig. 1 due to their too high reactivity with $\mathrm{PbO}_{2}$ impeding any significant growth of the EPR signal whatever the concentrations in $\mathrm{PbO}_{2}$. $\mathrm{PbO}_{2}$-oxidation of 3e affords only $17 \%$ conversion in $3^{\circ}$ as expected when less stabilized alkyl species is released from the meta-regioisomer of alkoxyamine. $\uparrow \uparrow$

\section{Chemical activation via $\mathrm{H}$-abstraction reaction}

The use of $\mathrm{PbO}_{2}$ as an oxidant generally also involves the transfer of protons. Since the reduction ( $\left(\mathrm{PbO}_{2}\right)$ is accompanied by proton transfer, it formally corresponds to a $\mathrm{H}$-atom transfer reaction. Accordingly, we have performed $\mathrm{H}$-abstraction reactions induced by the photolysis of di-tertbutyl peroxide.

$\S \S$ Several vigorous hand-shakings did not increase the EPR signal.

9ף Stabilities of $\mathbf{1}^{\cdot}, 3^{\cdot}-\mathbf{5}^{*}$ were investigated by EPR. $\mathbf{1}^{*}$ is stable in the presence of $\mathrm{PbO}_{2}, 3^{*}$ moderately stable, $4^{*}$ and $5^{*}$ decay quickly impeding all chances of detection when generated from their corresponding alkoxyamines. For $3^{\circ}$ and $\mathbf{4}^{*}$, the signal of another radical carrying a phosphorylated moiety is observed but not identified. This species is unstable and decay quickly however, the side species of $3^{*}$ is not obseverved during the oxidation of $\mathbf{3 a}$.

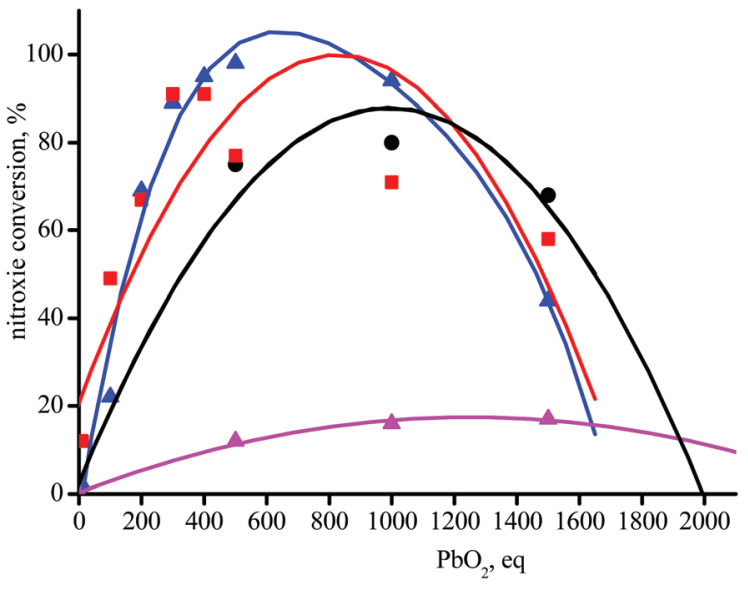

Fig. 1 Plots of nitroxide conversion vs. equivalents in $\mathrm{PbO}_{2}$ with $t-\mathrm{BuPh}$ as solvent for $\mathbf{1}^{\circ}$ (red squares), $2^{\circ}$ (black circles), and $3^{\circ}$ (blue and magenta triangles) from $1 \mathrm{a}, 2 \mathrm{a}, 3 \mathrm{a}$ and $3 \mathrm{e}$, respectively. Lines (second order polynomes) are for an easy reading of the trend.

The $t$-BuO radical (Scheme 3a) is able to primarily abstract the phenolic H-atom to generate a phenoxyl radical (Scheme 3d). ${ }^{43}$ The latter can undergo fragmentation into a nitroxide and a methyne quinone like-product (Scheme 3e). Indeed, as soon as light is turned on, in a solution containing 3a and di-tertbutyl peroxide EPR signal of $3^{*}$ raised affording around $80 \%$ conversion after a very long time (larger than 10 hours) of irradiation and for less than $5 \%(\mathrm{v} / \mathrm{v})$ of di-tertbutyl peroxide (Table 2).

Disappointingly, a large amount of $40 \%$ conversion 3 a into $3^{\circ}$ is observed after 12 hours of UV-irradiation in the absence of peroxide. Thus, $\mathbf{3 a}$ as well as $\mathbf{1 a}$ and $\mathbf{2 a}$ are light sensitive. Nevertheless, the kinetics of generation of $3^{*}$ are dramatically 


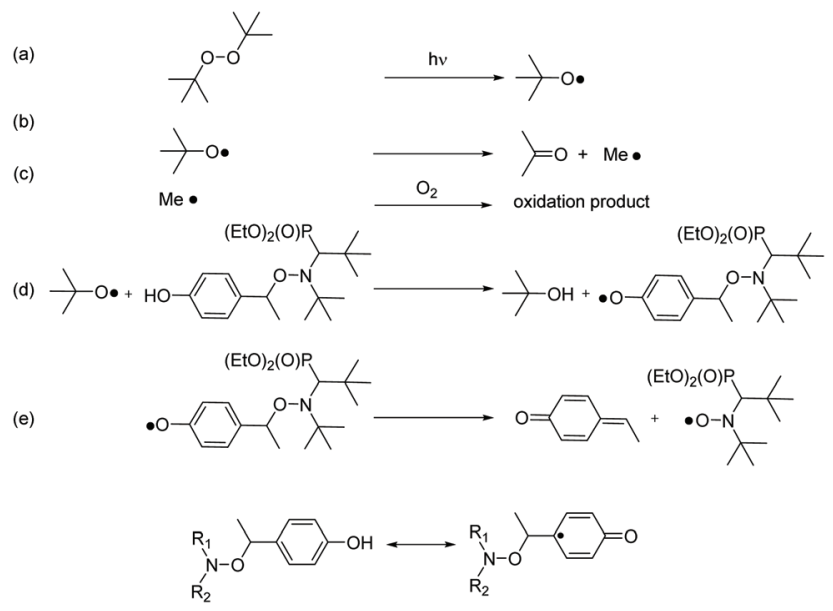

Scheme 3 Elementary reactions involved during the generation of 3 . under light-irradiation of a solution of $3 a$ with $\left(t-\mathrm{BuO}_{2}\right.$.

Table 2 Maximum conversion (\%) and the corresponding time ( $\left.t_{\max }\right)$ for the generation of $1^{-}-3^{*}$ by the photolysis of tert-butylbenzene solutions $(0.1 \mathrm{mM})$ of $1 \mathrm{a}-3 \mathrm{a}$, and $3 \mathrm{e}$ in the presence $(0 \%-10 \%)$ of di-tert-butyl peroxide $t-\mathrm{Bu}_{2} \mathrm{O}_{2}$ at room temperature

\begin{tabular}{llclr}
\hline Alkoxyamines & $\begin{array}{l}t \mathrm{Bu}_{2} \mathrm{O}_{2} \\
(\%, \mathrm{v} / \mathrm{v})\end{array}$ & Equivalents $^{a}$ & $\begin{array}{l}\text { Conversion } \\
(\%)\end{array}$ & $\begin{array}{l}t_{\max }{ }^{c} \\
(\mathrm{~min})\end{array}$ \\
\hline 1a & 0 & 0 & 24 & 300 \\
2a & 0 & 0 & 66 & 660 \\
3a & 0 & 0 & $49^{d}$ & 720 \\
3e & 0 & 0 & $43^{d}$ & 420 \\
2a & 0.1 & 66 & 63 & 720 \\
3a & 0.1 & 66 & 68 & 1260 \\
1a & 0.5 & 330 & 77 & 480 \\
2a & 0.5 & 330 & 67 & 540 \\
3a & 0.5 & 330 & 74 & 1020 \\
3e & 0.5 & 330 & 47 & 300 \\
2a & 1 & 660 & 62 & 240 \\
3a & 1 & 660 & 60 & 85 \\
3a & $5^{e}$ & 3300 & 49 & 75 \\
3a & 10 & 6600 & 39 & 85
\end{tabular}

${ }^{a}$ Density: $d=0.796 .{ }^{b}$ Highest conversion observed. ${ }^{c}$ Time for which the maximum conversion reported in the $4^{\text {th }}$ column is observed. ${ }^{d}$ When experiment was stopped. ${ }^{e}$ When $[3 \mathbf{a}]=1 \mathrm{mM}$, no significant differences are observed both in conversion and in kinetics.

faster in the presence of more than $1 \%$ of $(t \mathrm{BuO})_{2}$ than in its absence (Fig. 2), that is, during the first 3 hours of irradiation, kinetics for the generation of $3^{\circ}$ are the same for $0.1 \%$ in $(t \mathrm{BuO})_{2}$ and without whereas, in this time, amounts of $3^{\circ}$ reached a plateau and completely decayed for amounts in $(t \mathrm{BuO})_{2}$ larger than $1 \%$ (Fig. 2). Notably, the plateau is reached faster for lower amounts of $3^{\circ}$, i.e., $30 \%$ released in $1000 \mathrm{~s}$ in $10 \%(t \mathrm{BuO})_{2}$ versus $70 \%$ released in 10 hours for $0.5 \%$ in $(t \mathrm{BuO})_{2}$. This striking dependence on time for decomposition of $3 \mathbf{a}$ into nitroxide $3^{*}$ is due to several competitive reactions involving $3^{\circ}, t$-BuO', and side-products. Di-tertbutyl peroxide generates tert-butoxyl radicals under UV-irradiation (Scheme 3d). The latter reacts either by $\mathrm{H}$-abstraction on the phenol moiety of $3 \mathrm{a}$ to generate a transient phenoxyl radical (Scheme $3 \mathrm{~b}$ ) or by $\beta$-fragmentation to afford acetone and methyl radicals (Scheme $3 \mathrm{~b}$ ). These methyl radicals

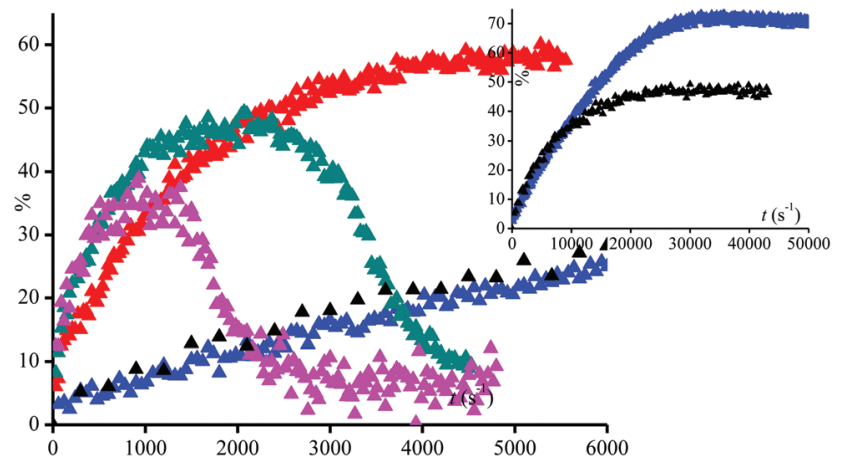

Fig. 2 UV-irradiation of $3 a(0.1 \mathrm{mM})$ in $t$-BuPh at $25{ }^{\circ} \mathrm{C}$ with various amounts $(\% \mathrm{v} / \mathrm{v})$ of $(t-\mathrm{BuO})_{2}(\mathbf{\Delta})$ none, $(\boldsymbol{\Delta}) 0.5 \%,(\boldsymbol{\Delta}) 1 \%,(\boldsymbol{\Delta}) 5 \%$, and $(\boldsymbol{\Delta})$ $10 \%$. Inset: Longer kinetics for conditions $(\mathbf{\Lambda})$ no $(t-B u O)_{2}$, and $(\boldsymbol{\Lambda}) 0.5 \%$ $(t-\mathrm{BuO})_{2}$.

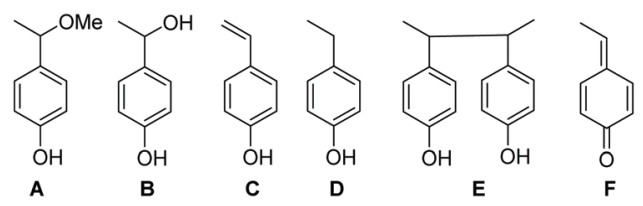

Chart 2 Potential product formed from $3 a\left(10^{-2} \mathrm{M}\right)$ upon the oneelectron oxidation process by $\mathrm{PbO}_{2}$ (500 eq.) in $\mathrm{MeOH}$ as solvent, at room temperature.

either react with $3^{\circ}$ by the coupling reaction leading to the formation of stable alkoxyamines, and, hence, to the decay of $3^{\circ}$ or they react with $\mathrm{O}_{2}$ to afford oxidation products or some other radicals able to react with $3^{\circ}$. Consequently, several of these reactions depend dramatically on concentration of starting materials $\left(t \mathrm{Bu}_{2} \mathrm{O}_{2}\right.$ and $\left.3 \mathrm{a}\right)$, of product $\left(3^{\circ}\right.$ and possibly acetone and methine quinone like-compound), and also of intermediates such as $t-\mathrm{BuO}^{\circ}$ and $\mathrm{Me}^{-}$radicals. Therefore, these differences in reactivity, account for the striking differences in conversion and in time to reach maximal conversion (Table 2).

\section{HPLC-ESI analysis}

For HPLC experiments, chemical oxidation of $3 \mathbf{a}, \mathbf{e}\left(10^{-2} \mathrm{M}\right)$ was performed in a $1: 1(\mathrm{v}: \mathrm{v}) \mathrm{MeOH} /$ water mixture and afforded the same EPR results as in $t$-BuPh as solvent when 500 eq. $\mathrm{PbO}_{2}$ were added. Authentic compounds displayed in Chart 2 are either prepared as described in literature ( $\mathbf{A}$ and $\mathbf{B}$ )

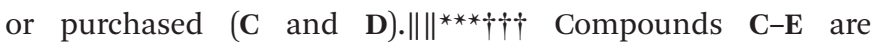
expected to be generated in the case of a mesolysis event

|| || Preparation of $\mathbf{E}$ and $\mathbf{F}$ is tedious, and as no unknown compounds is detected, no more efforts were devoted to their preparations.

*** Compounds issued from the degradation of $3 \mathbf{e}$ under chemical oxidation conditions were not prepared as the degradation processes are not clearly unveiled.

$\dagger \dagger$ Oxidations of $\mathbf{3 a}$ and $\mathbf{3 e}$ were performed in THF in the same conditions. In this case, the oxidation of $3 \mathbf{a}$ afforded mainly $3^{\circ}$ and $\mathbf{B}$ as main products due to the traces of water in THF. For 3e, results in THF were similar to those in $\mathrm{MeOH}$. See ESI. 


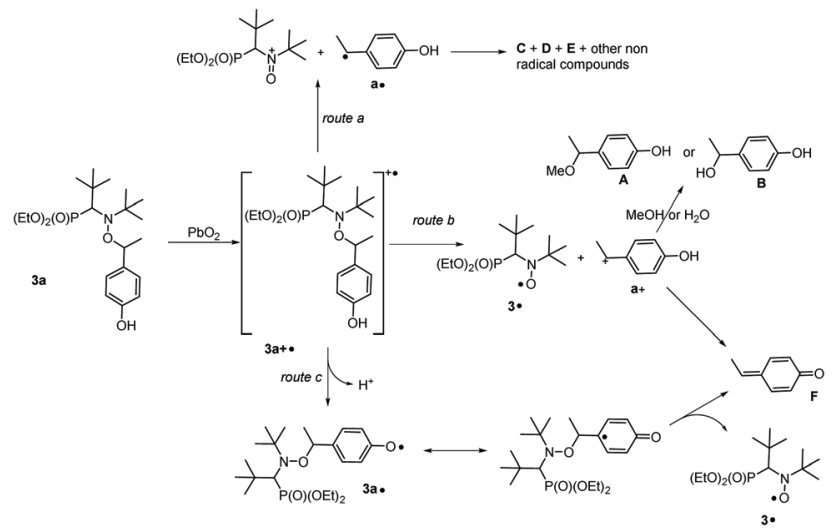

Scheme 4 Different routes of decay of $3 a+^{*}$ describing HPLC observations reported in Table 3 and ESI. $\dagger$

Table 3 Retention times in HPLC using UV detection $(\lambda=210 \mathrm{~nm})$, mass analysis (ESI-MS), and mass balances for pure A-C, $3 a$, and $3 \mathrm{~b}$, and for $3 \mathrm{a}$ and $3 \mathrm{e}$ in the presence of 500 eq. of $\mathrm{PbO}_{2}$ in a $\mathrm{MeOH} /$ water ( $\mathrm{v}: \mathrm{v}$ $1: 1)$ solvent mixture

\begin{tabular}{lllllll}
\hline & $t^{a}$ & $m_{\mathrm{e}} / z^{b}$ & $m_{\mathrm{o}} / z^{b}$ & $n_{\mathrm{a}}{ }^{c}$ & $n_{3} \cdot{ }^{c}$ & $n_{\mathrm{o}}{ }^{c}$ \\
\hline $\mathbf{A}$ & 11.2 & 153.2 & 121.2 & n.a. ${ }^{d}$ & n.a. ${ }^{d}$ & 1.0 \\
$\mathbf{C}$ & 12.5 & 121.2 & 121.2 & n.a. ${ }^{d}$ & n.a. ${ }^{d}$ & 1.0 \\
$\mathbf{3}^{\cdot}$ & 14.0 & 296.4 & 296.4 & n.a. ${ }^{d}$ & $0.80^{e}$ & n.a. ${ }^{d}$ \\
$\mathbf{3 a}^{f}$ & 15.6 & 416.2 & 416.2 & 0.56 & n.a. ${ }^{d}$ & n.a. ${ }^{d}$ \\
& 16.2 & & & 0.44 & & \\
$3 \mathbf{e}^{g}$ & 16.5 & 416.2 & 416.2 & 1.0 & n.a. ${ }^{d}$ & n.a. ${ }^{d}$ \\
$\mathbf{3 a}+\mathbf{P b O}_{2}$ & 11.1 & n.a. ${ }^{d}$ & 121.2 & n.a. ${ }^{d}$ & n.a. & $0.51^{h}$ \\
& 14.0 & & 296.2 & n.a. ${ }^{d}$ & 0.80 & n.a. ${ }^{d}$ \\
& 15.6 & & 416.2 & 0.05 & n.a. ${ }^{d}$ & n.a. ${ }^{d}$ \\
& 16.2 & & 416.2 & 0.11 & n.a. ${ }^{d}$ & n.a. ${ }^{d}$ \\
$\mathbf{3 e}+\mathbf{P b O}_{2}$ & 14.0 & n.a. ${ }^{d}$ & 296.2 & n.a. ${ }^{d}$ & 0.07 & n.a. ${ }^{d}$ \\
& 16.5 & & 416.2 & 0.91 & n.a. ${ }^{d}$ & n.a. ${ }^{d}$
\end{tabular}

${ }^{a}$ Retention time in min. ${ }^{b} m_{\mathrm{e}} / z$ and $m_{\mathrm{o}} / z$ are for the expected and observed masses by ESI-MS, respectively, in $\mathrm{MeOH} / \mathrm{H}_{2} \mathrm{O}(1: 1 \mathrm{v}: \mathrm{v})$, given at $\pm 0.1 \mathrm{u}$. ${ }^{c}$ In $10^{-8}$ moles at $\pm 0.01 . n_{\mathrm{a}}, n_{3^{*}}$, and $n_{\mathrm{o}}$ number of moles for alkoxyamines, $3^{\circ}$, and other molecules, respectively. ${ }^{d}$ n.a.: not applicable. ${ }^{e}$ As displayed in Fig. 3, 20\% of impurities are detected. ${ }^{f}$ Mixture of 2 diastereoisomers. ${ }^{g}$ Only one diastereoisomers was available. ${ }^{h}$ Amount of $A$.

releasing benzylic type radical and oxonium (route a in Scheme 4).

HPLC analysis of the decomposition of $\mathbf{3 e}$ (Table 3 ) displays only peaks corresponding to $\mathbf{3 e}$ (only $30 \%$ conversion) and to some traces of $3^{\circ}$ (less than $10 \%$ in agreement with EPR results) meaning that the pathways of decomposition affording $3^{*}$ are minor events (see section DFT calculations section and Fig. 7).

As displayed in Fig. 3, only $\mathbf{3 a}, \mathbf{3}^{\bullet}$ and $\mathbf{A}$ are observed for the decomposition of $\mathbf{3 a}$ in the presence of $\mathrm{PbO}_{2}$. No traces of other chemicals displayed in Chart 2 are detected. Mass balances (Table 3 ) for $\mathbf{3 a}$ ( $84 \%$ conversion) and $3^{\circ}$ (80\% conversion) agree with the EPR results. On the other hand, a clear discrepancy is observed in the mass balance for $3^{*}(8 \mathrm{nmol}$ against $5.1 \mathrm{nmol}$ for $\mathbf{A})$ meaning that most of the radical cation decomposes into nitroxide and benzylic-type carbo-
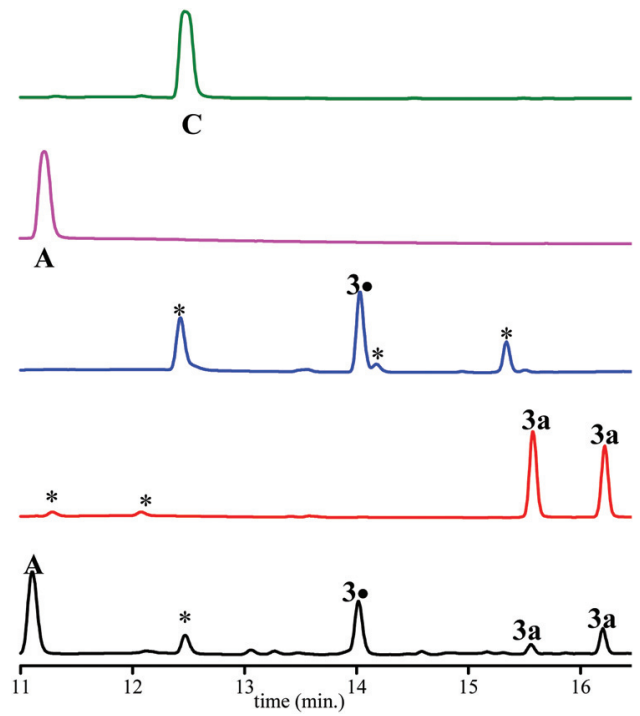

Fig. 3 HPLC signal of authentic compounds and of products for the chemical oxidation degradation of $3 \mathrm{a}$. Concentrations are at $10^{-2} \mathrm{M}$ in $\mathrm{MeOH} /$ water (1:1 v:v). From top to bottom, HPLC traces of pure C (magenta), pure A (green); "pure" 3" (blue), pure 3a (red), and decomposition (black) of $3 \mathrm{a}$ in the presence of $\mathrm{PbO}_{2}$ (500 eq.).

cation a+ (route b, Scheme 4) which, is scavenged by $\mathrm{MeOH}$ to generate $\mathbf{A}$ provided the elimination reaction to afford $\mathbf{C}$ does not compete. The discrepancy observed is likely due to the occurrence of route $c$ (Scheme 4) generating a phenoxyl radical $3 \mathbf{a}^{\circ}$ which decomposes into nitroxide $3^{\circ}$ and methine quinonetype compound $\mathbf{F}$ or to the loss of $\mathbf{H}+$ from $\mathbf{a}+$ to afford $\mathbf{F}$. The latter cannot be detected under our experimental conditions.

Importantly, only $\mathbf{3 a}, \mathbf{3}^{\mathbf{*}}$, and $\mathbf{C}$ are detected by ESI-MS (Table 3). Indeed, for $\mathbf{A}$ and $\mathbf{B}$, ESI detects only $\mathbf{C}$, meaning that $\mathrm{MeOH}$ - or water-elimination occurs in the course of the ESI experiment. The HPLC mass balance shows that the decomposition of the radical cation of alkoxyamine $3 \mathbf{a}+^{\bullet}$ does not occur through route a (Scheme 4).

The same experiments have been performed with $3 \mathrm{a}$ in THF affording very similar results except that a+ is scavenged by traces of water in THF to yield $\mathbf{B}$ (see ESI table and figure $\dagger$ ). When experiments are performed with $\mathbf{3 e}$, similar results to those reported in Table 3 are observed (see ESI table $\dagger$ ). Thus, all observations for $\mathbf{3 a}$ and $\mathbf{3 e}$ in $\mathbf{M e O H}$ /water mixture apply also to experiments performed in THF as solvent. It was assumed that the same reactivity would be expected for other phenol-based alkoxyamines not investigated by HPLC.

\section{pK $K_{\mathrm{a}}$ measurements}

Due to solubility issues of $3 a, T H F: \mathrm{D}_{2} \mathrm{O}(\mathrm{v} / \mathrm{v}$ 1/1) mixture was used for ${ }^{1} \mathrm{H}$ NMR (Fig. 4). $\mathrm{p} K_{\mathrm{a}}$ values of each diastereoisomer of 3a (Fig. 5) are given as $12.3( \pm 0.02)$ and $12.8( \pm 0.05)$ using eqn (1). ${ }^{44} \mathrm{p} K_{\mathrm{a}}$ Values of paravinylphenol are measured as 12.0 when recorded in the same conditions (see ESI $\dagger$ ).

$$
\delta_{\mathrm{pH}}=\delta+\frac{\delta_{\mathrm{H}^{+}}-\delta}{1+10^{\mathrm{p} K_{\mathrm{a}}-\mathrm{pH}}}
$$




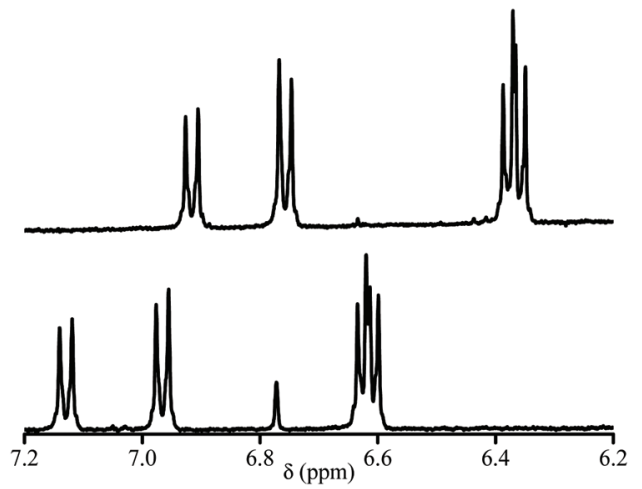

Fig. $4400 \mathrm{MHz}{ }^{1} \mathrm{H}$ NMR signal of the aromatic zone at $\mathrm{pH}=13$. (Top) and at $\mathrm{pH}=1.3$ (bottom) of $3 \mathrm{a}$ in THF.

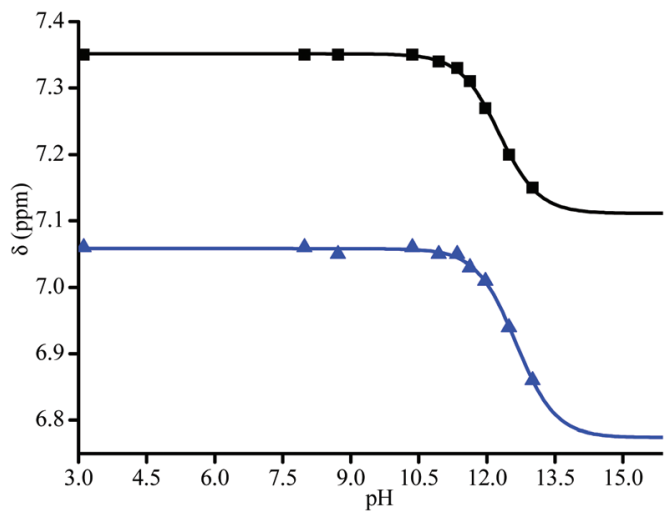

Fig. $5 \mathrm{pH}$ curves for diastereoisomers of $3 a(\boldsymbol{\Lambda}$ and $\boldsymbol{\nabla})$ by 2 peaks in the aromatic zone (see Fig. 4). Data were fitted with eqn (1).

\section{CIDNP experiments}

The experiments described above indicate that the formal abstraction of the phenolic $\mathrm{H}$ atom induces the formation of the nitroxyl radical. To shed light on the mechanism of the underlying reaction sequence at a $\mu$ s time scale, we performed photo-induced TR-CIDNP (Time-Resolved Chemically Induced Dynamic Nuclear Polarization) experiments. ${ }^{45,46}$ As an example, we present the results obtained with $\mathbf{3 a}$ (see ESI $\uparrow$ for more derivatives). We have used benzophenone (BP) as the photo-activated hydrogen acceptor. It reacts in an analogous way as the $t$-BuO ${ }^{\circ}$ radical (see above Scheme $3 \mathrm{~d}$ ) and can be conveniently activated at $366 \mathrm{~nm}$ (NdYAG laser, used in our CIDNP system). We have utilized this approach to successfully study various $\mathrm{H}$-transfer reactions. ${ }^{47,48}$

In the CIDNP experiment, free radical pairs are generated thermally or photochemically inside the strong magnetic field of the NMR magnet. At the time scale of the CIDNP experiment, the primary radicals undergo reactions, which are spin selective. This leads to a non-Boltzmann population of magnetic energy levels and manifests itself in NMR signals with "unusual" intensities, i.e. enhanced absorption or emission (enhancement factors up to $10^{5}$ ) when the corresponding products are formed via radical pairs. The intensities of these

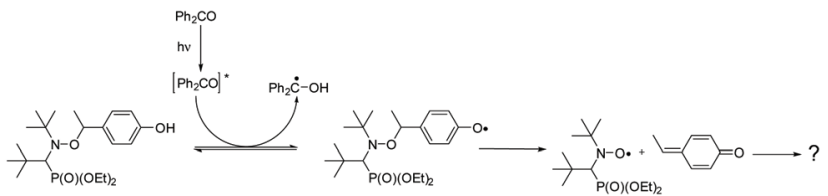

Scheme 5 generation of $3^{\circ}$ during the irradiation (NdYAG laser, $355 \mathrm{~nm}, 8 \mathrm{~ns})$ of benzophenone $(3 \mathrm{mM})$ in the presence of $3 \mathrm{a}(1 \mathrm{mM})$ at $25^{\circ} \mathrm{C}$ in acetonitrile- $d_{3} / \mathrm{D}_{2} \mathrm{O}$.

polarized signals (of the products) provide information about the isotropic hyperfine coupling constants in the short-lived radical intermediates. To produce primary radical pairs, we used the photo-induced (NdYAG laser, $355 \mathrm{~nm}, 8 \mathrm{~ns}$ ) reaction of the triplet-excited state of $\mathbf{B P}\left({ }^{{ }^{*}} \mathbf{B P}\right)$ with alkoxyamine in acetonitrile- $\mathrm{d}_{3} / \mathrm{D}_{2} \mathrm{O}$ (Scheme 5 ). Primarily, ${ }^{{ }^{*}} \mathbf{B P}$ should abstract the phenolic hydrogen ${ }^{49,50}$ and the corresponding follow-up products are observed in CIDNP spectrum with the chemical shifts representing the products and the polarized line intensities indicating the intermediate radicals (Scheme 5). As an example, the ${ }^{1} \mathrm{H}$ NMR and CIDNP spectra obtained from $\mathbf{3 a}$ together with assignments of selected lines are shown in Fig. 7. The most prominent polarizations in the CIDNP spectrum (7.7 ppm and 8-8.2 ppm) can be attributed to the reversible hydrogen transfer from $\mathbf{B P H} \mathbf{H}^{*}$ to $\mathbf{3}^{\bullet}$ re-generating $\mathbf{B P}$ and 3a (Scheme 5). This is in concert with an intermediate phenoxyl radical where the predominant spin population is located on the phenyl ring of 3a in agreement with B3LYP/ TZVP calculations. ${ }^{51,52}$ Clearly, an electron transfer producing a basically nitrogen centred radical cation from $\mathbf{3 a}$ to ${ }^{3} \mathbf{B P}$, would have produced an entirely different polarization pattern than that observed in our experiment (see ESI $\dagger$ for the com-

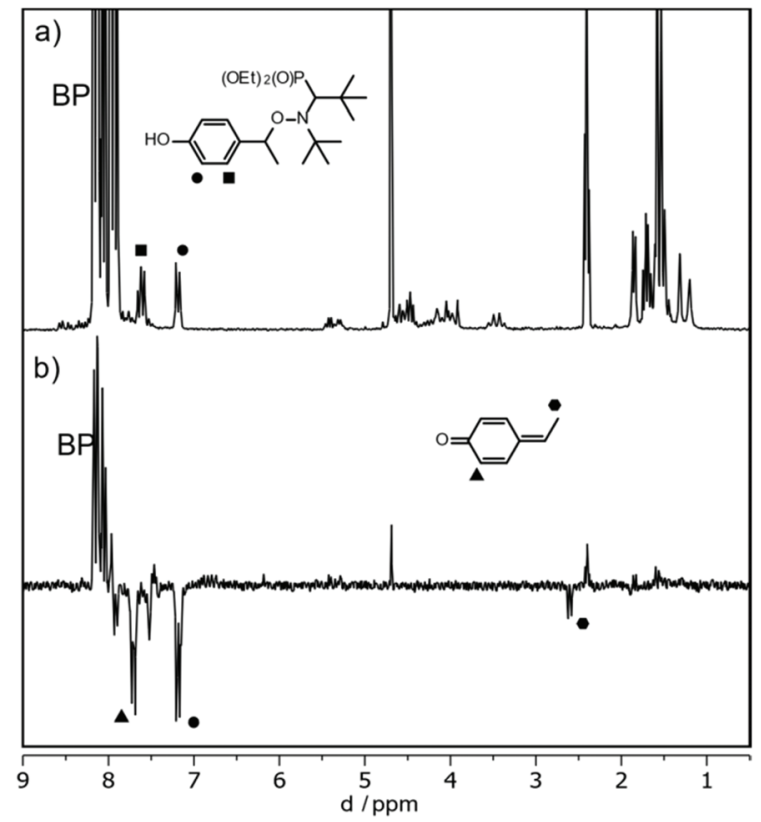

Fig. $6{ }^{1} \mathrm{H}$ NMR (a) and (b) CIDNP spectrum of $3 \mathrm{a}$ and BP in Acetonitrile$\mathrm{d}_{3} / \mathrm{D}_{2} \mathrm{O}$ recorded $2 \mu \mathrm{s}$ after the laser flash ( $355 \mathrm{~nm}, 8 \mathrm{~ns}$ ). 
parison with additional radicals). The remaining polarizations at $2.55 \mathrm{ppm}$ (doublet) and $7.7 \mathrm{ppm}$ (doublet) can be assigned to a methyne quinone like-product $\mathbf{F}$ (Chart 2 and Fig. 6) formed via the homolytic cleavage of the $\mathrm{C}-\mathrm{O}$ bond in $3 \mathrm{a}^{\circ}$. This intermediate is too short lived to be detected in the steady-state NMR taken after the CIDNP experiment. The fragmentation of $3 \mathrm{a}^{\circ}$ yielding nitroxyl radical $3^{\circ}$ is confirmed by the detection of the corresponding EPR spectrum taken from the NMR tube after accomplishing the NMR experiment.

For derivative $\mathbf{3 b}$, in which the phenolic hydrogen is replaced by the benzyl group, the fragmentation reaction cannot be established by CIDNP (see ESI $\dagger$ ); moreover, weak EPR signal is detected. This clearly indicates that the abstraction of the phenolic hydrogen is crucial for the formation of nitroxyl radical $3^{\circ}$.

\section{DFT calculations}

We have performed calculations (M06-2X/6-31+G(d,p) level of theory $)^{53}$ for radical cations and phenoxyl radicals based on parent 3a and 3e. In Fig. 7, we have displayed the most exergonic (or the lowest endergonic) pathways for the decomposition of $\mathbf{3 a}$ and 3e under oxidative conditions (see the ESI $\uparrow$ for pathways with highly endergonic $\Delta G$ values). For 3a there are three pathways starting from the same radical cation $3 \mathbf{a}^{*}$ as intermediate which are preferable. One pathway (Path $3 \mathrm{a}(\mathrm{I})$ ) involves the cleavage of the $\mathrm{N}-\mathrm{O}$ bond and the formation of an aminium cation $\mathbf{N}+$ and alkoxyl radical $\mathbf{O}^{*}\left(\Delta G=-51 \mathrm{~kJ} \mathrm{~mol}^{-1}\right)$. The second radical-cation-based process produces the desired nitroxide together with benzyl cation a+ (Path $3 \mathrm{a}(\mathrm{II}), \Delta G=-27 \mathrm{~kJ}$ $\mathrm{mol}^{-1}$ ). The third one, the reaction via neutral phenoxyl radical $3 \mathbf{a}^{\circ}$ provides nitroxide $3^{\circ}$ and 4-ethylidenecyclohexa-2,5-dien-1one $\mathbf{F}$ (Path $3 \mathrm{a}(\mathrm{III}), \Delta G=-49 \mathrm{~kJ} \mathrm{~mol}^{-1}$ ). The calculations predict two likely reactions for $\mathbf{3 e}$ and both are based on radical cation precursors $3 \mathbf{e}^{\circ}$ : one being analogous to Path $3 \mathrm{a}(\mathrm{I})$ and yielding aminium cation $\mathbf{N}+$ and alkoxyl radical $\mathbf{O}^{\prime}$ (Path $3 \mathbf{e}(\mathrm{I}), \Delta G=$ $-55 \mathrm{~kJ} \mathrm{~mol}^{-1}$ ); the second resembling Path $3 \mathrm{a}$ (II) giving the desired nitroxide $3^{\circ}$ and benzyl cation e+ (Path $3 \mathbf{e}(\mathrm{II}), \Delta G=+9 \mathrm{~kJ}$ $\mathrm{mol}^{-1}$ ). In contrast to $\mathbf{3 a}$, paths $\mathbf{3 e}(\mathrm{III})$ is disregarded due to its too high value of $\Delta G$, i.e., $72 \mathrm{~kJ} \mathrm{~mol}^{-1}$. As delineated in Fig. 7, for both the radical cations $3 \mathbf{a}+^{\circ}$ and $3 \mathbf{e}+^{\circ}$ issued from the oxidation of $\mathbf{3 a}$ and $\mathbf{3 e}$, respectively, there is a connection between oxidation and HAT routes as the radical cation affords phenoxyl radical by loss of proton. Taking into account EPR, CIDNP, and HPLC results, paths $\mathbf{3 a}(\mathrm{I})$ and $\mathbf{3 e}(\mathrm{III})$ are disregarded.

\section{Discussion}

\section{Chemical activation via $\mathbf{H}$-abstraction reaction}

The generation of $3 \mathrm{a}^{\bullet}$ through $\mathrm{H}$-abstraction by $t$-BuO ${ }^{\bullet}$ radicals and its $\beta$-fragmentation into $3^{\circ}$ and $\mathbf{F}$, which are entangled with (several) light-initiated reactions, are nicely confirmed by CIDNP experiments by using benzophenone as radical

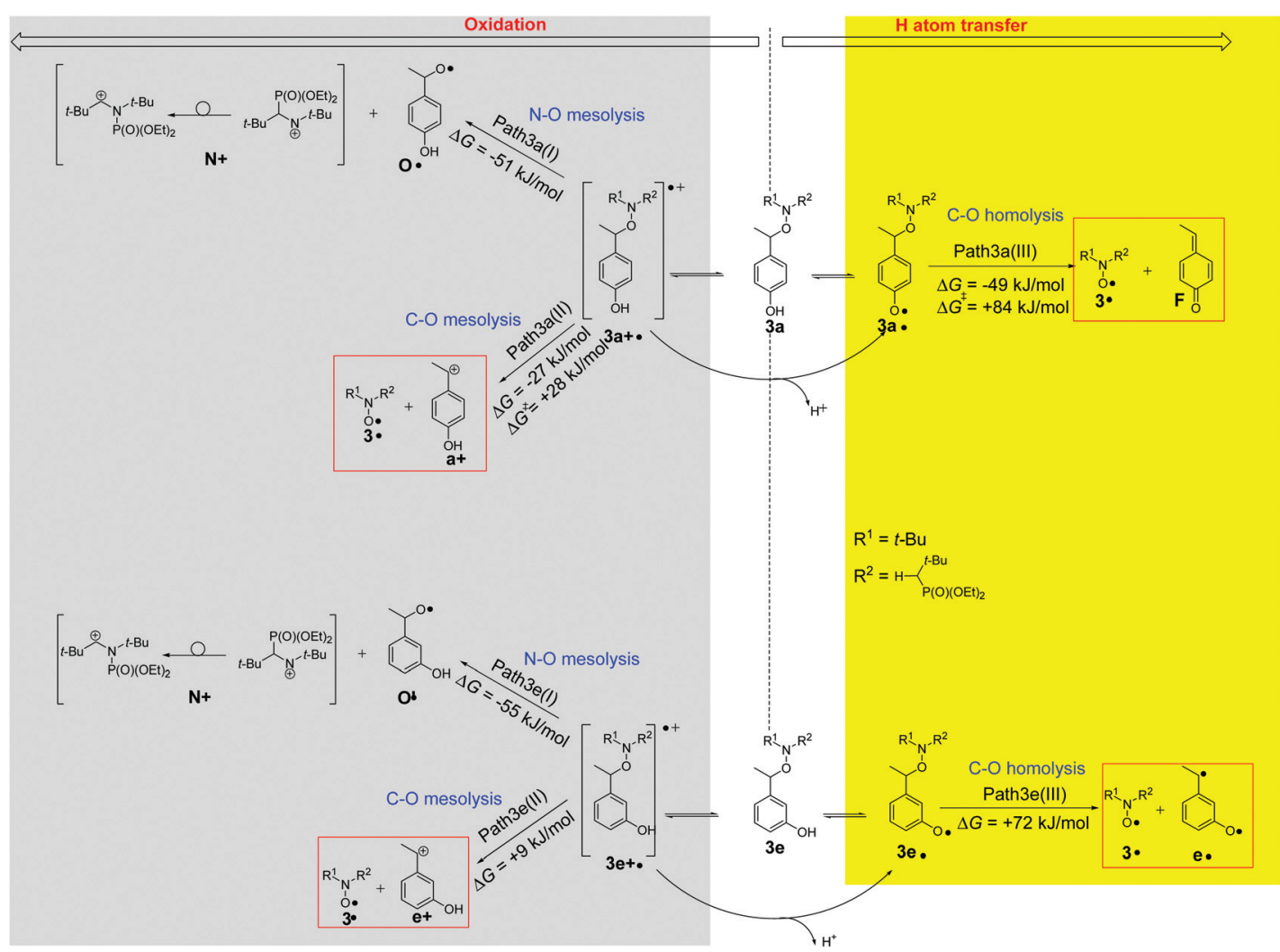

Fig. 7 Selected (preferred) pathways of decomposition radicals based on 3a and 3e according to M06-2X/6-31+G(d,p) calculations. Reactions leading to the release of nitroxyl radicals are marked with red boxes. 
initiator. Moreover, DFT calculations support the occurrence of Path3a(III) which exhibit clear negative value of $\Delta G$ with $\Delta G^{\ddagger}$ lower than $90 \mathrm{~kJ} \mathrm{~mol}^{-1}$ as expected for the occurrence of spontaneous and instantaneous reactions. As the same kinetic trends are observed (Table 2) for $\mathbf{1 a}$, and $\mathbf{2 a}$, it is assumed that the observations for $\mathbf{3 a}$ apply to these also.

\section{Activation by electron transfer event}

Previous studies have examined the behaviour of amoniumyl radical cations generated upon oxidation of alkoxyamines by electrochemical $^{19-23}$ or photoredox ${ }^{24}$ methods. Depending on the leaving group and co-reactants present, the oxidation can either be (a) reversible, or lead to mesolytic cleavage of either the (b) CO-N bond to form aminyl radicals, or cleavage of the $\mathrm{C}-\mathrm{ON}$ to form either (c) an oxoamonium and carbon-centred radical or (d) a nitroxide and carbocation. Alternatively, cleavage can occur via (e) $\mathrm{S}_{\mathrm{N}}$ 2-type reactions with nucleophiles, which may include trace water, the solvent or electrolyte. Importantly, in the case of 1c, only route (d) has been observed experimentally in anhydrous solvents, ${ }^{19,23}$ and one would expect analogous behaviour for $3 \mathbf{c}$, given that the leaving group is identical.

Whatever the amounts of $\mathrm{PbO}_{2}$ added to a solution of $3 \mathrm{c}$ in $t$-BuPh, less than $4 \%$ of signal is detected by EPR. When the same experiments are performed with $3 \mathbf{e}$, less than $20 \%$ of $3{ }^{\circ}$ are detected by EPR (Fig. 1) in agreement with HPLC measurements (Table 3), and calculations meaning that path(II) (path3e(II) in Fig. 7) is a minor event in the generation of $3^{*}$ by chemical oxidation process when the released benzylic-cation is not stabilized. This also holds for other alkoxyamines investigated in this article (vide infra).

DFT calculations on the homolysis routes (Fig. 7) show only two relevant processes of fragmentations (other are displayed as ESI $\dagger$ ): (i) mesolysis of the $\mathrm{C}-\mathrm{ON}$ bond in $3 \mathbf{a}^{\circ}$ affording nitroxide $3^{*}$ and benzyl-type carbocation $\mathrm{a}+\left(\Delta G_{\mathrm{b}}=-27 \mathrm{~kJ} \mathrm{~mol}^{-1}\right.$, and $\Delta G^{\ddagger}=28 \mathrm{~kJ} \mathrm{~mol}^{-1}$, Path3a(II) in Fig. 7); and (ii) via proton release from $3 \mathbf{a}^{*}$ to generate phenoxyl radical $3 \mathbf{a}^{\circ}+t+$ which collapses into nitroxide $3^{\circ}$ and methine-quinone type compound $\mathbf{F}\left(\Delta G_{\mathrm{c}}=-49 \mathrm{~kJ} \mathrm{~mol}^{-1}\right.$, route $\mathrm{c}$ in Scheme 4 and Path3a (III) in Fig. 7), i.e. Proton-Coupled Electron Transfer $(\mathrm{PCET})^{27,54}$ followed by a $\beta$-fragmentation event. The mesolysis of the $\mathrm{C}-\mathrm{ON}$ affording oxonium and stabilized styryl-type radical $\mathbf{a}^{\cdot}$ (see ESI $\dagger$ ), is disregarded due to both strongly disfavoured $\Delta G$ value $\left(\Delta G_{\mathrm{a}}=75 \mathrm{~kJ} \mathrm{~mol}^{-1}\right.$, see $\left.\mathrm{ESI}^{\dagger}\right)$ and an almost quantitative generation of $3^{\circ}$.

Indeed, DFT calculated negative $\Delta G$ values and $\Delta G^{\ddagger}$ values lower than $100 \mathrm{~kJ} \mathrm{~mol}^{-1}$ confirm the spontaneous and instantaneous generation of $3^{*}$. Moreover, the lower activation $\Delta G^{\ddagger}$ for path3a(II) $\left(\Delta G_{\mathrm{b}}^{\ddagger}=28 \mathrm{~kJ} \mathrm{~mol}^{-1}\right)$ than for path3a(III) $\left(\Delta G_{\mathrm{c}}^{\ddagger}=84 \mathrm{~kJ}\right.$ $\mathrm{mol}^{-1}$ ) in Fig. 7 denotes a favoured path3a(II) over path3a(III) as highlighted by the mass balance in HPLC (Table 3).

$\$+$ Noteworthily, the addition of $\mathrm{PbO}_{2}$ on molecules exhibiting phenol moieties is well known to generate phenoxyl radical through a Proton-Coupled Electron Transfer (PCET, see ref. 54 and 27) via the generation of radical cation and loss of proton to provide a phenoxyl radical.

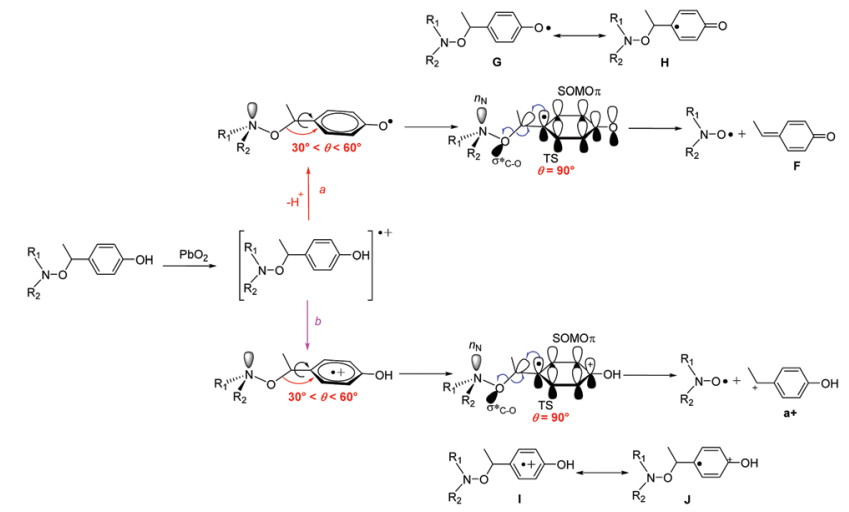

Scheme 6 Generation of nitroxide from alkoxyamine through a PCET process coupled with the $\beta$-fragmentation of phenoxyl radical (route a) and the mesolysis of radical cation (route b), and geometrical parameters and orbital interaction at their respective TS.

The quantitative generation of $\mathbf{1}^{\bullet}$ and $2^{*}$ is observed upon addition of $\mathrm{PbO}_{2}$ to a solution of $\mathbf{1 a}$ and $2 \mathrm{a}$, meaning that comments done for 3a hold.

Addition of $\mathrm{PbO}_{2}$ to $\mathbf{4 a}$ and $5 \mathbf{a}$ does not generate significant amounts of the corresponding nitroxides $4^{\circ}$ and $5^{\circ}$ due to their low stability in the experimental conditions. $\uparrow$ Nevertheless, it is assumed that the same chemistry as described for 3a holds for $4 \mathbf{a}$ and $5 \mathbf{a}$.

\section{Impact on the fragmentation pathway}

It has to be mentioned that, whatever the experimental conditions, the phenoxyl radical and radical cation are not detected by EPR meaning a very fast decomposition into the nitroxide. Thus, the generation of nitroxide cannot occur as described in Scheme 2 in which flattening at $\mathrm{N}$ - and $\mathrm{C}$-atoms is required. Recent DFT calculations showed that $\mathrm{C}-\mathrm{ON}$ bond homolysis is controlled by two geometrical requirements (Scheme 2): (i) flattening at $\mathrm{N}$ - and $\mathrm{C}$-atoms, and (ii) dihedral angle $\theta\langle$ OCaryl $\rangle$ close to $90^{\circ}$ and dihedral angle $\theta_{1}\left\langle n_{\mathrm{N}} \mathrm{NOC}\right\rangle$ close to $0^{\circ}$. It was also shown that alkoxyamines exhibiting angle $\theta$ close to $90^{\circ}$ and $\theta_{1}$ close to $0^{\circ}$ are stable at room temperature meaning that the flattening at $\mathrm{C}$ - and $\mathrm{N}$-atoms are the key events which must occur during the raise of temperature when homolysis is performed. Thus, two pathways of decay are offered to the radical cation: route (a) for which the radical cation collapses into nitroxide and benzylic-type cation and route (b) which correspond to the release of phenoxyl radical. Interestingly, both routes exhibit strong similarities for stereoelectronic interactions at TS (Scheme 6), i.e., mesomeric forms $\mathbf{H}$ of phenoxyl radical $\mathbf{G}$ and $\mathbf{J}$ of radical cation $\mathbf{I}$ display a significant spin population at the position ipso. Such forms $\mathbf{H} / \mathbf{J}$ favour the rotation around the $\mathrm{C}$-aryl bond to shift $\theta$ angle from $60^{\circ} \S \S \S$ to $90^{\circ}$ (see TS section in ESI $\dagger$ ) aiming to favour hyperconjugative interaction $\mathrm{SOMO} \pi \rightarrow \sigma^{*}{ }_{\mathrm{C}-\mathrm{O}}$ between the

$\S \S \S$ For most 3-based alkoxyamines carrying an aryl moiety on the alkyl fragment, the dihedral angle $\theta$ is close to $60^{\circ}$. 
SOMO of $\pi$-type and the antibonding orbital $\sigma^{*}{ }_{\mathrm{C}-\mathrm{O}}$ of the $\mathrm{C}-\mathrm{O}$ bond. Such an interaction at TS favours undoubtedly the $\beta$-fragmentation event of the $\mathrm{O}-\mathrm{C}$ bond affording two highly stabilized molecules: a nitroxide and a conjugated keto diene despite aromaticity is lost for the fragmentation of phenoxyl radical, and a nitroxide and a benzylic-type cation for the mesolysis of the radical cation. In such a process involving early TS, i.e., reactant-like TS, neither the unfavoured $\mathrm{N}$-flattening event nor the $\mathrm{N}-\mathrm{O}$ bond rotation occur leading to a room temperature spontaneously and instantaneously thermodynamically-driven fragmentation.

Our experimental observations and the computational results indicate that the very efficient production of the nitroxide $\left(\right.$ e.g. $\left.3^{\circ}\right)$ is based either on the primary generation of a phenoxyl radical via hydrogen abstraction or PCET (which cannot be distinguished at the time scale of our experiments) or the mesolysis of the corresponding radical cation. The main prerequisite for an efficient reaction, however, is that an alkyl fragment carrying a $p$-phenolic moiety as exemplified with 1a-5a. Here the release of the nitroxide can be either triggered thermally by $\mathrm{PbO}_{2}$ or by photo-induced reactions. Thus, the caged nitroxides introduced in this work have the potential of being applied in biology and polymer chemistry (e.g., as selectively activable labels). It is likely that the scope of (photo)oxidants can be enhanced.

\section{Experimental}

\section{Synthetic procedures}

Solvents and reactants for the preparation of alkoxyamines were used as received. Routine reaction monitoring was performed using silica gel 60 F254 TLC plates; spots were visualized upon exposure to UV light and a phosphomolybdic acid solution in EtOH, followed by heating. Purifications were performed on Reveleris ${ }^{\circledR}$ X2 Flash System BUCHI Switzerland. Cartouches flash Reveleris ${ }^{\circledR}$ et GraceResolv ${ }^{\mathrm{TM}}$ : silica $40 \mu \mathrm{m}$. ${ }^{1} \mathrm{H},{ }^{13} \mathrm{C}$, and ${ }^{31} \mathrm{P}$ NMR spectra were recorded in $\mathrm{CDCl}_{3}$ on a 300 or $400 \mathrm{MHz}$ spectrometer. Chemical shifts $(\delta)$ in ppm were reported using residual nondeuterated solvents as internal references for ${ }^{1} \mathrm{H}$ and ${ }^{13} \mathrm{C}$ NMR spectra, and $85 \%$ $\mathrm{H}_{3} \mathrm{PO}_{4}$ for ${ }^{31} \mathrm{P}-\mathrm{NMR}$ spectra. High-resolution mass spectra (HRMS) were performed on a SYNAPT G2 HDMS (Waters) spectrometer equipped with a pneumatically assisted atmospheric pressure ionization source (API). Positive mode electrospray ionization was used on samples: electrospray voltage (ISV): $2800 \mathrm{~V}$; opening voltage (OR): $20 \mathrm{~V}$; nebulizer gas pressure (nitrogen): $800 \mathrm{~L} \mathrm{~h}^{-1}$. Low resolution mass spectra were recorded on the ion trap AB SCIEX 3200 QTRAP equipped with an electrospray source. The parent ion $[\mathrm{M}+\mathrm{H}]^{+}$is quoted.

Benzylation of vinylphenol. To a stirred solution of vinylphenol (10\% w/w in propylene glycol, $5.0 \mathrm{~g}, 4.16 \mathrm{mmol}, 1 \mathrm{eq}$.) in acetone $(70 \mathrm{~mL})$, was added $\mathrm{K}_{2} \mathrm{CO}_{3}(3.8 \mathrm{~g}, 27.04 \mathrm{mmol}$, 6.5 eq.), then benzylbromide ( $2.3 \mathrm{~g}, 13.31 \mathrm{mmol}, 3.2 \mathrm{eq}$.). The reaction was stirred at room temperature for $24 \mathrm{~h}$. After this time, the solvent was evaporated, diluted with EtOAc $(80 \mathrm{~mL})$ and $3 \mathrm{M}$ aq. $\mathrm{HCl}$ was carefully added. The layers were separated, and the organic phase was washed with water, brine and dried over $\mathrm{MgSO}_{4}$. After concentration under reduced pressure, the residue was purified by column chromatography (petroleum ether/EtOAc; gradient: $100 \%$ to $80 \%$ ) to afford 6 (743 mg, 85\%).

General procedure for the preparation of $\mathbf{1 b}-\mathbf{5 b}$. To a stirred solution of Salen ligand (0.15 eq.) in i-PrOH was added $\mathrm{MnCl}_{2}$ (0.15 eq.) in an open flask. After 30 minutes of stirring at room temperature, a solution of nitroxyde $\mathbf{1}^{\circ}-\mathbf{5}^{*}$ (1 eq.) and 4 -vinylbenzylphenol 6 (1.1 eq.) in i-PrOH was added first, then solid $\mathrm{NaBH}_{4}$ (5 eq.) in small portions. The resulting suspension was stirred at room temperature for $7 \mathrm{~h}$. It was then diluted with EtOAc $(100 \mathrm{~mL})$ and $1 \mathrm{M}$ aq. $\mathrm{HCl}$ was carefully added. Solid $\mathrm{NaHCO}_{3}$ was then added until neutralization. The layers were separated, and the organic phase was washed with water, brine and dried over $\mathrm{MgSO}_{4}$. After concentration under reduced pressure, the residue was purified by column chromatography (petroleum ether/EtOAc) to afford the corresponding alkoxyamines $\mathbf{1 b} \mathbf{- 5} \mathbf{b}$.

General procedure of hydrogenation for the preparation of 1a-5a. To a stirred solution of benzylated alkoxyamine $\mathbf{1 b}-\mathbf{5 b}$ ( 1 eq.) in EtOAc was added $\mathrm{Pd} / \mathrm{C}(10 \% \mathrm{w} / \mathrm{w})$ with a flow of hydrogen for 30 minutes. After a complete consumption of starting material monitored by TLC, the solution was filtered on Celite. It was then concentrated under reduced pressure and the residue was purified, if necessary, by column chromatography (petroleum ether/EtOAc) to afford the corresponding alkoxyamines 1a-5a.

Synthesis of 1-(1-(4-(benzyloxy)phenyl)ethoxy)-2,2,6,6-tetramethylpiperidine (1b). Alkoxyamines $\mathbf{1 b}$ was prepared according to the general procedure using Salen ligand (87 $\mathrm{mg}$, $0.324 \mathrm{mmol}, 0.15$ eq.), $\mathrm{MnCl}_{2}$ (64 mg, $0.324 \mathrm{mmol}, 0.15$ eq.), $\mathbf{1}^{*}$ (338 mg, $2.161 \mathrm{mmol}, 1.0$ eq.), 4-vinylbenzylphenol (500 mg, 2.378 mmol, 1.1 eq.) and $\mathrm{NaBH}_{4}$ (409 mg, $10.805 \mathrm{mmol}$, 5.0 eq.). Alkoxyamine was purified by automatic flash column chromatography (petroleum ether/EtOAc; gradient: $100 \%$ to $80 \%$ ) to afford $\mathbf{1 b}(516 \mathrm{mg}, 65 \%)$, white solid; m.p.: $100{ }^{\circ} \mathrm{C}$; $R_{\mathrm{f}}=0.75\left(\mathrm{EP} /\right.$ EtOAc 96:4); ${ }^{1} \mathrm{H}$ NMR (300 $\left.\mathrm{MHz}, \mathrm{CDCl}_{3}\right)$ $\delta$ 7.49-7.30 (m, 5H), $7.25(\mathrm{~d}, J=8.7 \mathrm{~Hz}, 2 \mathrm{H}), 6.93(\mathrm{~d}, J=8.7 \mathrm{~Hz}$, $2 \mathrm{H}), 5.06(\mathrm{~s}, 2 \mathrm{H}), 4.75$ (q, $J=6.7 \mathrm{~Hz}, 1 \mathrm{H}), 1.47$ (d, $J=6.7 \mathrm{~Hz}$, $3 \mathrm{H}), 1.45-0.99(\mathrm{~m}, 15 \mathrm{H}), 0.68(\mathrm{~s}, 3 \mathrm{H}) .{ }^{13} \mathrm{C} \mathrm{NMR}(75 \mathrm{MHz}$, $\left.\mathrm{CDCl}_{3}\right) \delta 157.7(\mathrm{C}), 138.3(\mathrm{C}), 137.2(\mathrm{C}), 128.5(2 \times \mathrm{CH}), 127.9$ $(\mathrm{CH}), 127.8(2 \times \mathrm{CH}), 127.5(2 \times \mathrm{CH}), 114.3(2 \times \mathrm{CH}), 82.4(\mathrm{CH})$, $70.0\left(\mathrm{CH}_{2}\right), 59.7(2 \times \mathrm{C}), 40.3\left(2 \times \mathrm{CH}_{2}\right), 34.4\left(2 \times \mathrm{CH}_{3}\right), 23.2$ $\left(\mathrm{CH}_{3}\right), 20.2\left(2 \times \mathrm{CH}_{3}\right), 17.2\left(\mathrm{CH}_{2}\right)$. HRMS $\mathrm{m} / \mathrm{z}$ (ESI) Calcd for $\mathrm{C}_{24} \mathrm{H}_{34} \mathrm{NO}_{2}^{+}[\mathrm{M}+\mathrm{H}]^{+}$368.2584 Found: 368.2581.

Synthesis of 1-(1-(4-(benzyloxy)phenyl)ethoxy)-2,2,5,5-tetramethylpyrrolidine (2b). Alkoxyamines $\mathbf{2 b}$ was prepared according to the general procedure using Salen ligand (85 mg, $0.316 \mathrm{mmol}, 0.15$ eq.), $\mathrm{MnCl}_{2}$ (63 mg, $0.316 \mathrm{mmol}, 0.15 \mathrm{eq}$.), $2^{\bullet}$ (300 mg, $2.110 \mathrm{mmol}, 1.0$ eq.), 4-vinylbenzylphenol (532 mg, $2.532 \mathrm{mmol}, 1.2$ eq.) and $\mathrm{NaBH}_{4}$ (399 mg, $10.550 \mathrm{mmol}$, 5.0 eq.). Alkoxyamine was purified by automatic flash column chromatography (petroleum ether/EtOAc; gradient: $100 \%$ to 
$80 \%$ ) to afford $2 \mathbf{b}(566 \mathrm{mg}, 76 \%)$, white solid; m.p.: $59{ }^{\circ} \mathrm{C} ; R_{\mathrm{f}}=$ 0.73 (EP/EtOAc 96:4); ${ }^{1} \mathrm{H}$ NMR (300 MHz, $\left.\mathrm{CDCl}_{3}\right) \delta$ 7.51-7.35 $(\mathrm{m}, 5 \mathrm{H}), 7.31(\mathrm{~d}, J=8.7 \mathrm{~Hz}, 2 \mathrm{H}), 6.98(\mathrm{~d}, J=8.7 \mathrm{~Hz}, 2 \mathrm{H}), 5.09$ $(\mathrm{s}, 2 \mathrm{H}), 4.67(\mathrm{q}, J=6.6 \mathrm{~Hz}, 1 \mathrm{H}), 1.62-145(\mathrm{~m}, 4 \mathrm{H}), 1.50(\mathrm{~d}, J=$ $6.6 \mathrm{~Hz}, 3 \mathrm{H}), 1.31$ (s, 3H), $1.21(\mathrm{~s}, 3 \mathrm{H}), 1.08$ (s, 3H), 0.73 (s, 3H). ${ }^{13} \mathrm{C}$ NMR (75 MHz, $\mathrm{CDCl}_{3}$ ) $\delta 158.0(\mathrm{C}), 137.5$ (C), $137.2(\mathrm{C})$, $128.5(2 \times \mathrm{CH}), 128.2(2 \times \mathrm{CH}), 127.8(\mathrm{CH}), 127.4(2 \times \mathrm{CH})$, $114.2(2 \times \mathrm{CH}), 81.6(\mathrm{CH}), 70.0\left(\mathrm{CH}_{2}\right), 64.2(\mathrm{C}), 63.2(\mathrm{C}), 36.1$ $\left(\mathrm{CH}_{2}\right), 35.4\left(\mathrm{CH}_{2}\right), 31.2\left(\mathrm{CH}_{3}\right), 31.1\left(\mathrm{CH}_{3}\right), 24.3\left(\mathrm{CH}_{3}\right), 22.8$ $\left(\mathrm{CH}_{3}\right), 22.1\left(\mathrm{CH}_{3}\right)$. HRMS m/z (ESI) Calcd for $\mathrm{C}_{23} \mathrm{H}_{32} \mathrm{NO}_{2}{ }^{+}$ $[\mathrm{M}+\mathrm{H}]^{+}$354.2428 Found: 354.2422 .

Synthesis of diethyl(1-((1-(4-(benzyloxy)phenyl)ethoxy) (tert-butyl)amino)-2,2-dimethylpropyl)phosphonate

(3b).

Alkoxyamines $\mathbf{3 b}$ was prepared according to the general procedure using Salen ligand (137 mg, $0.510 \mathrm{mmol}, 0.15$ eq.), $\mathrm{MnCl}_{2}$ (100 mg, $0.510 \mathrm{mmol}, 0.15$ eq.), 3* (1.0 g, $3.401 \mathrm{mmol}$, 1.0 eq.), 4-vinylbenzylphenol (858 mg, $4.081 \mathrm{mmol}, 1.2$ eq.) and $\mathrm{NaBH}_{4}$ (643 mg, $17.005 \mathrm{mmol}, 5.0$ eq.). The solvent was evaporated to give the crude product as mixture of diastereoisomers. The diastereoisomers were separated by automatic flash column chromatography (petroleum ether/EtOAc; gradient: $100 \%$ to $50 \%)$ to afford $(R R / S S)-3 \mathbf{b}(600 \mathrm{mg}, 35 \%)$ and $(R S /$ $S R)-3 \mathbf{b}(548 \mathrm{mg}, 32 \%)$. $(R R / S S)-3 \mathbf{b}$; pale yellow oil; $R_{\mathrm{f}}=0.54(\mathrm{EP} /$ EtOAc 4:1); ${ }^{1} \mathrm{H}$ NMR (400 MHz, $\left.\mathrm{CDCl}_{3}\right) \delta 7.46-7.31(\mathrm{~m}, 5 \mathrm{H})$, $7.23(\mathrm{~d}, J=8.6 \mathrm{~Hz}, 2 \mathrm{H}), 6.91(\mathrm{~d}, J=8.7 \mathrm{~Hz}, 2 \mathrm{H}), 5.05(\mathrm{~s}, 2 \mathrm{H})$, $4.96(\mathrm{q}, J=6.7 \mathrm{~Hz}, 1 \mathrm{H}), 4.38-4.31(\mathrm{~m}, 1 \mathrm{H}), 4.23-4.04(\mathrm{~m}, 2 \mathrm{H})$, 4.04-3.89 (m, 1H), $3.35\left(\mathrm{~d}, J_{\mathrm{H}-\mathrm{P}}=26.2 \mathrm{~Hz}, 1 \mathrm{H}\right), 1.59(\mathrm{~d}, J=$ $6.7 \mathrm{~Hz}, 3 \mathrm{H}), 1.35-1.30(\mathrm{~m}, 6 \mathrm{H}), 1.25(\mathrm{~s}, 9 \mathrm{H}), 0.85(\mathrm{~s}, 9 \mathrm{H})$. ${ }^{31} \mathrm{P}$ NMR (121 MHz, $\left.\mathrm{CDCl}_{3}\right) \delta$ 25.82. ${ }^{13} \mathrm{C} \mathrm{NMR}(75 \mathrm{MHz}$, Acetone) $\delta 152.1(\mathrm{C}), 132.0(\mathrm{C}), 131.3(\mathrm{C}), 122.8(4 \times \mathrm{CH}), 122.1$ $(\mathrm{CH}), 121.7(2 \times \mathrm{CH}), 108.5(2 \times \mathrm{CH}), 78.4(\mathrm{CH}), 64.2\left(\mathrm{CH}_{2}\right)$, $64.2\left(\mathrm{~d}, J_{\mathrm{C}-\mathrm{P}}=138.9 \mathrm{~Hz}, \mathrm{CH}\right), 55.8\left(\mathrm{~d}, J_{\mathrm{C}-\mathrm{P}}=6.5 \mathrm{~Hz}, \mathrm{CH}_{2}\right), 55.4$ (C), $53.1\left(\mathrm{~d}, J_{\mathrm{C}-\mathrm{P}}=8.2 \mathrm{~Hz}, \mathrm{CH}_{2}\right), 29.8\left(\mathrm{~d}, J_{\mathrm{C}-\mathrm{P}}=5.6 \mathrm{~Hz}, \mathrm{C}\right), 24.5$ $\left(\mathrm{d}, J_{\mathrm{C}-\mathrm{P}}=6.1 \mathrm{~Hz}, 3 \times \mathrm{CH}_{3}\right), 22.8\left(3 \times \mathrm{CH}_{3}\right), 17.8\left(\mathrm{CH}_{3}\right), 11.0(\mathrm{~d}$, $\left.J_{\mathrm{C}-\mathrm{P}}=5.7 \mathrm{~Hz}, \mathrm{CH}_{3}\right), 10.5\left(\mathrm{~d}, J_{\mathrm{C}-\mathrm{P}}=6.6 \mathrm{~Hz}, \mathrm{CH}_{3}\right) . \mathrm{HRMS} \mathrm{m} / \mathrm{z}$ (ESI) Calcd for $\mathrm{C}_{28} \mathrm{H}_{45} \mathrm{NO}_{5} \mathrm{P}^{+}[\mathrm{M}+\mathrm{H}]^{+} 505.3030$ Found: 505.3031. $(R S / S R)-3 \mathbf{b}$; pale yellow oil; $R_{\mathrm{f}}=0.67$ (EP/EtOAc $\left.4: 1\right)$; ${ }^{1} \mathrm{H}$ NMR (400 MHz, $\left.\mathrm{CDCl}_{3}\right) \delta 7.31(\mathrm{~d}, J=8.7 \mathrm{~Hz}, 2 \mathrm{H}), 7.35-7.18$ $(\mathrm{m}, 5 \mathrm{H}), 6.81(\mathrm{~d}, J=8.7 \mathrm{~Hz}, 2 \mathrm{H}), 5.13(\mathrm{q}, J=6.6 \mathrm{~Hz}, 1 \mathrm{H}), 4.95$ $(\mathrm{s}, 2 \mathrm{H}), 4.08-3.84(\mathrm{~m}, 1 \mathrm{H}), 3.85-3.69(\mathrm{~m}, 1 \mathrm{H}), 3.46-3.30(\mathrm{~m}$, $1 \mathrm{H}), 3.32\left(\mathrm{~d}, J_{\mathrm{H}-\mathrm{P}}=26.0 \mathrm{~Hz}, 1 \mathrm{H}\right), 3.26-3.10(\mathrm{~m}, 1 \mathrm{H}), 1.45(\mathrm{~d}, J=$ $6.6 \mathrm{~Hz}, 3 \mathrm{H}), 1.16(\mathrm{t}, J=7.1 \mathrm{~Hz}, 3 \mathrm{H}), 1.13(\mathrm{~s}, 9 \mathrm{H}), 1.11(\mathrm{~s}, 9 \mathrm{H})$, $0.81(\mathrm{t}, J=7.1 \mathrm{~Hz}, 3 \mathrm{H}) .{ }^{31} \mathrm{P} \mathrm{NMR}\left(121 \mathrm{MHz}, \mathrm{CDCl}_{3}\right) \delta 24.62 .{ }^{13} \mathrm{C}$ NMR (101 MHz, $\left.\mathrm{CDCl}_{3}\right) \delta 158.0$ (C), 137.1 (C), 135.7 (C), 129.1 $(2 \times \mathrm{CH}), 128.4(2 \times \mathrm{CH}), 127.7(\mathrm{CH}), 127.3(2 \times \mathrm{CH}), 114.2(2 \times$ $\mathrm{CH}), 77.7(\mathrm{CH}), 70.1$ (d, JC-P $=139.3 \mathrm{~Hz}, \mathrm{CH}), 69.8\left(\mathrm{CH}_{2}\right), 61.6$ (d, $\left.J_{\mathrm{C}-\mathrm{P}}=6.3 \mathrm{~Hz}, \mathrm{CH}_{2}\right), 61.1(\mathrm{C}), 58.5\left(\mathrm{~d}, J_{\mathrm{C}-\mathrm{P}}=7.5 \mathrm{~Hz}, \mathrm{CH}_{2}\right.$ ), $35.3\left(\mathrm{~d}, J_{\mathrm{C}-\mathrm{P}}=5.1 \mathrm{~Hz}, \mathrm{C}\right), 30.6\left(\mathrm{~d}, J_{\mathrm{C}-\mathrm{P}}=6.0 \mathrm{~Hz}, 3 \times \mathrm{CH}_{3}\right), 28.1$ $\left(3 \times \mathrm{CH}_{3}\right), 20.9\left(\mathrm{CH}_{3}\right), 16.3\left(\mathrm{~d}, J_{\mathrm{C}-\mathrm{P}}=5.9 \mathrm{~Hz}, \mathrm{CH}_{3}\right), 16.1$ (d, $\left.J_{\mathrm{C}-\mathrm{P}}=6.9 \mathrm{~Hz}, \mathrm{CH}_{3}\right)$. HRMS $m / z$ (ESI) Calcd for $\mathrm{C}_{28} \mathrm{H}_{45} \mathrm{NO}_{5} \mathrm{P}^{+}[\mathrm{M}$ $+\mathrm{H}]^{+}$505.3030 Found: 505.3031

Synthesis of diethyl(1-((1-(4-(benzyloxy)phenyl)ethoxy) (1-hydroxy-2-methylpropan-2-yl)amino)-2,2-dimethylpropyl) phosphonate (4b). Alkoxyamines $4 \mathbf{b}$ was prepared according to the general procedure using Salen ligand $(130 \mathrm{mg}$, $0.483 \mathrm{mmol}, 0.15$ eq.), $\mathrm{MnCl}_{2}$ (95 mg, $0.483 \mathrm{mmol}, 0.15$ eq.), $\mathbf{4}^{\bullet}$
(1.0 g, $3.226 \mathrm{mmol}, 1.0$ eq.), 4-vinylbenzylphenol (814 mg, 3.871 mmol, 1.2 eq.) and $\mathrm{NaBH}_{4}(611 \mathrm{mg}, 16.130 \mathrm{mmol}$, 5.0 eq.). The solvent was evaporated to give the crude product as mixture of diastereoisomers. The diastereoisomers were separated by automatic flash column chromatography (petroleum ether/EtOAc; gradient: $100 \%$ to $40 \%)$ to afford $(R R / S S)-\mathbf{4 b}$ (521 $\mathrm{mg}, 31 \%)$ and $(R S / S R)-4 \mathbf{b}(454 \mathrm{mg}, 27 \%) .(R R / S S)-\mathbf{4 b}$; white solid; m.p.: $65{ }^{\circ} \mathrm{C} ; R_{\mathrm{f}}=0.66$ (EP/EtOAc $\left.7: 3\right) ;{ }^{1} \mathrm{H}$ NMR (400 MHz, CDCl3) $\delta 7.63-7.42(\mathrm{~m}, 2 \mathrm{H}), 7.42-7.36(\mathrm{~m}, 2 \mathrm{H}), 7.34$ $(\mathrm{d}, J=7.2 \mathrm{~Hz}, 1 \mathrm{H}), 7.29(\mathrm{~d}, J=8.6 \mathrm{~Hz}, 2 \mathrm{H}), 6.95(\mathrm{~d}, J=8.7 \mathrm{~Hz}$, $2 \mathrm{H}), 5.06(\mathrm{~s}, 2 \mathrm{H}), 4.94(\mathrm{q}, J=6.6 \mathrm{~Hz}, 1 \mathrm{H}), 4.29(\mathrm{~m}, 1 \mathrm{H})$, 4.23-3.92 (m, 3H), 3.67 (d, $\left.J_{\mathrm{H}-\mathrm{P}}=26.7 \mathrm{~Hz}, 1 \mathrm{H}\right), 3.46(\mathrm{~d}, J=12.0$ $\mathrm{Hz}, 1 \mathrm{H}), 3.09$ (d, $J=12.0 \mathrm{~Hz}, 1 \mathrm{H}), 1.56$ (d, $J=6.6 \mathrm{~Hz}, 3 \mathrm{H}), 1.37$ (t, $J=7.1 \mathrm{~Hz}, 6 \mathrm{H}), 1.24(\mathrm{~s}, 9 \mathrm{H}), 1.05(\mathrm{~s}, 3 \mathrm{H}), 0.80(\mathrm{~s}, 3 \mathrm{H}) .{ }^{31} \mathrm{P}$ NMR (121 MHz, $\left.\mathrm{CDCl}_{3}\right) \delta$ 26.89. $\left.{ }^{13} \mathrm{C} \mathrm{NMR} \mathrm{(75} \mathrm{MHz,} \mathrm{CDCl}_{3}\right) \delta$ 158.0 (C), 137.1 (C), 136.9 (C), $128.5(2 \times \mathrm{CH}), 128.0(2 \times \mathrm{CH})$, $127.8(\mathrm{CH}), 127.5(2 \times \mathrm{CH}), 114.4(2 \times \mathrm{CH}), 83.85(\mathrm{CH}), 69.8$ $\left(\mathrm{CH}_{2}\right), 69.3\left(\mathrm{~d}, J_{\mathrm{C}-\mathrm{P}}=139.3 \mathrm{~Hz}, \mathrm{CH}\right), 67.4\left(\mathrm{CH}_{2}\right), 64.7(\mathrm{C}), 61.7$ $\left(\mathrm{d}, J_{\mathrm{C}-\mathrm{P}}=6.3 \mathrm{~Hz}, \mathrm{CH}_{2}\right), 60.3\left(\mathrm{~d}, J_{\mathrm{C}-\mathrm{P}}=6.3 \mathrm{~Hz}, \mathrm{CH}_{2}\right), 35.6(\mathrm{~d}$, $\left.J_{\mathrm{C}-\mathrm{P}}=4.6 \mathrm{~Hz}, \mathrm{C}\right), 30.1\left(\mathrm{~d}, J_{\mathrm{C}-\mathrm{P}}=5.6 \mathrm{~Hz}, 3 \times \mathrm{CH}_{3}\right), 26.6\left(\mathrm{CH}_{3}\right)$, $23.8\left(\mathrm{CH}_{3}\right), 23.0\left(\mathrm{CH}_{3}\right), 16.5\left(\mathrm{~d}, J_{\mathrm{C}-\mathrm{P}}=5.8 \mathrm{~Hz}, \mathrm{CH}_{3}\right), 16.2(\mathrm{~d}$, $\left.J_{\mathrm{C}-\mathrm{P}}=6.6 \mathrm{~Hz}, \mathrm{CH}_{3}\right)$. HRMS $m / z$ (ESI) Calcd for $\mathrm{C}_{28} \mathrm{H}_{45} \mathrm{NO}_{6} \mathrm{P}^{+}$ $[\mathrm{M}+\mathrm{H}]^{+}$522.2979 Found: 522.2977. $(R S / S R)-4 \mathbf{b}$; pale yellow oil; $R_{\mathrm{f}}=0.74(\mathrm{EP} /$ EtOAc $7: 3) ;{ }^{1} \mathrm{H}$ NMR (400 $\left.\mathrm{MHz}, \mathrm{CDCl}_{3}\right) \delta$ 7.38-7.16 (m, 5H), $7.26(\mathrm{~d}, J=8.6 \mathrm{~Hz}, 2 \mathrm{H}), 6.82(\mathrm{~d}, J=8.7 \mathrm{~Hz}$, $2 \mathrm{H}), 5.01$ (q, $J=6.5 \mathrm{~Hz}, 1 \mathrm{H}), 4.94(\mathrm{~s}, 2 \mathrm{H}), 4.48(\mathrm{~s}, 1 \mathrm{H})$, $3.90-3.51(\mathrm{~m}, 5 \mathrm{H}), 3.71\left(\mathrm{~d}, J_{\mathrm{H}-\mathrm{P}}=27.2 \mathrm{~Hz}, 1 \mathrm{H}\right), 3.44(\mathrm{~d}, J=12.2$ $\mathrm{Hz}, 1 \mathrm{H}), 1.44(\mathrm{~d}, J=6.6 \mathrm{~Hz}, 3 \mathrm{H}), 1.17(\mathrm{~s}, 3 \mathrm{H}), 1.11-1.03(\mathrm{~m}$, 15H), 1.00 (t, $J=7.0 \mathrm{~Hz}, 3 \mathrm{H}) .{ }^{31} \mathrm{P}$ NMR (121 MHz, $\left.\mathrm{CDCl}_{3}\right) \delta$ 26.61. ${ }^{13} \mathrm{C}$ NMR (101 MHz, CDCl3) $\delta 157.7$ (C), 137.0 (C), $135.84(\mathrm{C}), 128.4(2 \times \mathrm{CH}), 127.7(\mathrm{CH}), 127.7(2 \times \mathrm{CH}), 127.3$ $(2 \times \mathrm{CH}), 114.3(2 \times \mathrm{CH}), 77.6(\mathrm{CH}), 69.8\left(\mathrm{CH}_{2}\right), 69.6\left(\mathrm{~d}, J_{\mathrm{C}-\mathrm{P}}=\right.$ 136.4 Hz, CH), $67.8\left(\mathrm{CH}_{2}\right), 64.5(\mathrm{C}), 61.9\left(\mathrm{~d}, J_{\mathrm{C}-\mathrm{P}}=6.5 \mathrm{~Hz}, \mathrm{CH}_{2}\right)$, $60.3\left(\mathrm{~d}, J_{\mathrm{C}-\mathrm{P}}=7.8 \mathrm{~Hz}, \mathrm{CH}_{2}\right), 35.2\left(\mathrm{~d}, J_{\mathrm{C}-\mathrm{P}}=4.2 \mathrm{~Hz}, \mathrm{C}\right), 30.5(\mathrm{~d}$, $\left.J_{\mathrm{C}-\mathrm{P}}=5.7 \mathrm{~Hz}, 3 \times \mathrm{CH}_{3}\right), 26.5\left(\mathrm{~d}, J_{\mathrm{C}-\mathrm{P}}=75.2 \mathrm{~Hz}, \mathrm{CH}_{3}\right), 24.0$ $\left(\mathrm{CH}_{3}\right), 21.7\left(\mathrm{CH}_{3}\right), 16.2\left(\mathrm{~d}, J_{\mathrm{C}-\mathrm{P}}=5.6 \mathrm{~Hz}, \mathrm{CH}_{3}\right), 15.9\left(\mathrm{~d}, J_{\mathrm{C}-\mathrm{P}}=\right.$ $6.6 \mathrm{~Hz}, \mathrm{CH}_{3}$ ). HRMS m/z (ESI) Calcd for $\mathrm{C}_{28} \mathrm{H}_{45} \mathrm{NO}_{6} \mathrm{P}^{+}[\mathrm{M}+\mathrm{H}]^{+}$ 522.2979 Found: 522.2975.

Synthesis of $\mathrm{O}$-(1-(4-(benzyloxy)phenyl)ethyl)- $\mathrm{N}, \mathrm{N}$-di-tertbutylhydroxylamine (5b). Alkoxyamines $\mathbf{5 b}$ was prepared according to the general procedure using Salen ligand (138 mg, $0.516 \mathrm{mmol}, 0.15$ eq.), $\mathrm{MnCl}_{2}$ (102 mg, $0.516 \mathrm{mmol}$, 0.15 eq.), $5^{*}$ (500 mg, $3.443 \mathrm{mmol}, 1.0$ eq.), 4-vinylbenzylphenol (869 mg, $4.131 \mathrm{mmol}, 1.2$ eq.) and $\mathrm{NaBH}_{4}$ (651 mg, $17.215 \mathrm{mmol}, 5.0$ eq.). Alkoxyamine was purified by automatic flash column chromatography (petroleum ether/EtOAc; gradient: $100 \%$ to $80 \%)$ to afford $\mathbf{5 b}(709 \mathrm{mg}, 58 \%)$, white solid; m.p.: $104{ }^{\circ} \mathrm{C} ; R_{\mathrm{f}}=0.63$ (EP/EtOAc 96:4); ${ }^{1} \mathrm{H}$ NMR $(400 \mathrm{MHz}$, $\left.\mathrm{CDCl}_{3}\right) \delta 7.51-7.32(\mathrm{~m}, 5 \mathrm{H}), 7.26(\mathrm{~d}, J=8.6 \mathrm{~Hz}, 2 \mathrm{H}), 6.94(\mathrm{~d}, J=$ $8.6 \mathrm{~Hz}, 2 \mathrm{H}), 5.07$ (s, 2H), 4.81 (q, $J=6.7 \mathrm{~Hz}, 1 \mathrm{H}), 1.49$ (d, $J=6.7$ $\mathrm{Hz}, 3 \mathrm{H}), 1.32$ (s, 9H), 1.05 (s, 9H). ${ }^{13} \mathrm{C} \mathrm{NMR}\left(101 \mathrm{MHz}, \mathrm{CDCl}_{3}\right.$ ) $\delta 157.8(\mathrm{C}), 137.7(\mathrm{C}), 137.2(\mathrm{C}), 128.5(2 \times \mathrm{CH}), 128.2(2 \times \mathrm{CH})$, $127.8(\mathrm{CH}), 127.5(2 \times \mathrm{CH}), 114.2(2 \times \mathrm{CH}), 82.0(\mathrm{CH}), 70.0$ $\left(\mathrm{CH}_{2}\right), 61.8(\mathrm{C}), 61.7(\mathrm{C}), 30.6\left(6 \times \mathrm{CH}_{3}\right), 22.3\left(\mathrm{CH}_{3}\right)$. HRMS $\mathrm{m} / \mathrm{z}$ (ESI) Calcd for $\mathrm{C}_{23} \mathrm{H}_{34} \mathrm{NO}_{2}{ }^{+}[\mathrm{M}+\mathrm{H}]^{+} 356.2584$ Found: 356.2579 . 
Synthesis of 1-(1-(3-(benzyloxy)phenyl)ethoxy)-2,2,6,6-tetramethylpiperidine (1d). Alkoxyamines 1d was prepared according to the general procedure using Salen ligand (52 $\mathrm{mg}$, $0.195 \mathrm{mmol}, 0.15$ eq.), $\mathrm{MnCl}_{2}$ (40 mg, $0.195 \mathrm{mmol}, 0.15$ eq.), $1^{*}$ (203 mg, $1.297 \mathrm{mmol}, 1.0$ eq.), 3-vinylbenzylphenol (300 mg, 1.426 mmol, 1.1 eq.) and $\mathrm{NaBH}_{4}(245 \mathrm{mg}, 6.485 \mathrm{mmol}$, 5.0 eq.). Alkoxyamine was purified by automatic flash column chromatography (petroleum ether/EtOAc; gradient: $100 \%$ to $80 \%)$ to afford 1d (119 mg, 25\%), white solid; m.p.: $101{ }^{\circ} \mathrm{C} ; R_{\mathrm{f}}$ $=0.75(\mathrm{EP} /$ EtOAc $96: 4) ;{ }^{1} \mathrm{H}$ NMR $\left(400 \mathrm{MHz}, \mathrm{CDCl}_{3}\right) \delta 7.37(\mathrm{~m}$, $2 \mathrm{H}), 7.28(\mathrm{~m}, 3 \mathrm{H}), 7.14(\mathrm{~m}, 1 \mathrm{H}), 6.89(\mathrm{~m}, 1 \mathrm{H}), 6.83(\mathrm{~m}, 1 \mathrm{H})$, $6.77(\mathrm{~m}, 1 \mathrm{H}), 4.99(\mathrm{~s}, 2 \mathrm{H}), 4.67(\mathrm{q}, J=6.6 \mathrm{~Hz}, 1 \mathrm{H}), 1.40(\mathrm{~m}, 6 \mathrm{H})$, $1.38(\mathrm{~d}, J=6.7 \mathrm{~Hz}, 3 \mathrm{H}), 1.20(\mathrm{~s}, 3 \mathrm{H}), 1.08(\mathrm{~s}, 3 \mathrm{H}), 0.94(\mathrm{~s}, 3 \mathrm{H})$, 0.62 (s, 3H). ${ }^{13} \mathrm{C}$ NMR (101 MHz, $\left.\mathrm{CDCl}_{3}\right) \delta 158.7$ (C), $147.6(\mathrm{C})$, $137.2(\mathrm{C}), 129.0(\mathrm{CH}), 128.5(2 \times \mathrm{CH}), 127.9(\mathrm{CH}), 127.6(2 \times$ $\mathrm{CH}), 119.3(\mathrm{CH}), 113.2(\mathrm{CH}), 113.1(\mathrm{CH}), 83.1(\mathrm{CH}), 70.0\left(\mathrm{CH}_{2}\right)$, $59.7(2 \times \mathrm{C}), 40.4\left(2 \times \mathrm{CH}_{2}\right), 34.5\left(\mathrm{CH}_{3}\right), 34.1\left(\mathrm{CH}_{3}\right), 23.6\left(\mathrm{CH}_{3}\right)$, $20.4\left(2 \times \mathrm{CH}_{3}\right), 17.2\left(\mathrm{CH}_{2}\right)$. HRMS $\mathrm{m} / \mathrm{z}$ (ESI) Calcd for $\mathrm{C}_{24} \mathrm{H}_{34} \mathrm{NO}_{2}^{+}[\mathrm{M}+\mathrm{H}]^{+}$368.2584 Found: 368.2588.

Synthesis of diethyl(1-((1-(3-(benzyloxy)phenyl)ethoxy) (tert-butyl)amino)-2,2-dimethylpropyl)phosphonate

(3d).

Alkoxyamines 3d was prepared according to the general procedure using Salen ligand (69 $\mathrm{mg}, 0.259 \mathrm{mmol}, 0.15$ eq.), $\mathrm{MnCl}_{2}$ (51 mg, $0.259 \mathrm{mmol}, 0.15$ eq.), 3* (504 mg, $1.729 \mathrm{mmol}$, 1.0 eq.), 3-vinylbenzylphenol (400 mg, $1.902 \mathrm{mmol}, 1.1$ eq.) and $\mathrm{NaBH}_{4}$ (196 mg, $5.187 \mathrm{mmol}, 3.0$ eq.). The solvent was evaporated to give the crude product as mixture of diastereoisomers. The diastereoisomers were separated by automatic flash column chromatography (petroleum ether/EtOAc; gradient: $100 \%$ to $50 \%)$ to afford $(R R / S S)-3 \mathrm{~d}(245 \mathrm{mg}, 28 \%)$ and $(R S /$ $S R)-3 d(235 \mathrm{mg}, 27 \%)$. (RR/SS)-3d; pale yellow oil; $R_{\mathrm{f}}=0.54(\mathrm{EP} /$ EtOAc $4: 1) ;{ }^{1} \mathrm{H}$ NMR (400 MHz, $\left.\mathrm{CDCl}_{3}\right) \delta 7.38(\mathrm{~m}, 5 \mathrm{H}), 7.22(\mathrm{t}$, $J=7.8 \mathrm{~Hz}, 1 \mathrm{H}), 6.91(\mathrm{~m}, 2 \mathrm{H}), 6.85(\mathrm{~m}, 1 \mathrm{H}), 5.07(\mathrm{~s}, 2 \mathrm{H}), 4.96(\mathrm{q}$, $J=6.7 \mathrm{~Hz}, 1 \mathrm{H}), 4.35(\mathrm{~m}, 1 \mathrm{H}), 4.10(\mathrm{~m}, 2 \mathrm{H}), 3.98(\mathrm{~m}, 1 \mathrm{H}), 3.34$ $\left(\mathrm{d}, J_{\mathrm{H}-\mathrm{P}}=26.1 \mathrm{~Hz}, 1 \mathrm{H}\right), 1.59(\mathrm{~d}, J=6.8 \mathrm{~Hz}, 3 \mathrm{H}), 1.34(\mathrm{t}, J=7.1$ $\mathrm{Hz}, 3 \mathrm{H}), 1.31$ (t, J = 7.1 Hz, 3H), 1.24 (s, 9H), 0.85 (s, 9H). ${ }^{31} \mathrm{P}$ $\mathrm{NMR}\left(121 \mathrm{MHz}, \mathrm{CDCl}_{3}\right) \delta$ 25.91. $\left.{ }^{13} \mathrm{C} \mathrm{NMR} \mathrm{(101} \mathrm{MHz}, \mathrm{CDCl}_{3}\right)$ $\delta 158.6(\mathrm{C}), 147.3(\mathrm{C}), 137.1(\mathrm{C}), 129.0(\mathrm{CH}), 128.6(2 \times \mathrm{CH})$, $127.9(\mathrm{CH}), 127.4(2 \times \mathrm{CH}), 119.9(\mathrm{CH}), 113.8(\mathrm{CH}), 113.5(\mathrm{CH})$, $85.5(\mathrm{CH}), 69.9\left(\mathrm{CH}_{2}\right), 69.9\left(\mathrm{~d}, J_{\mathrm{C}-\mathrm{P}}=138.5 \mathrm{~Hz}, \mathrm{CH}\right), 61.6(\mathrm{~d}$, $\left.J_{\mathrm{C}-\mathrm{P}}=6.3 \mathrm{~Hz}, \mathrm{CH}_{2}\right), 61.25(\mathrm{C}), 58.8\left(\mathrm{~d}, J_{\mathrm{C}-\mathrm{P}}=7.5 \mathrm{~Hz}, \mathrm{CH}_{2}\right), 35.6$ $\left(\mathrm{d}, J_{\mathrm{C}-\mathrm{P}}=5.8 \mathrm{~Hz}, \mathrm{C}\right), 30.1\left(\mathrm{~d}, J_{\mathrm{C}-\mathrm{P}}=5.8 \mathrm{~Hz}, 3 \times \mathrm{CH}_{3}\right), 28.5(3 \times$ $\left.\mathrm{CH}_{3}\right), 24.1\left(\mathrm{CH}_{3}\right), 16.8\left(\mathrm{~d}, J_{\mathrm{C}-\mathrm{P}}=5.5 \mathrm{~Hz}, \mathrm{CH}_{3}\right), 16.3\left(\mathrm{~d}, J_{\mathrm{C}-\mathrm{P}}=\right.$ $6.7 \mathrm{~Hz}, \mathrm{CH}_{3}$ ). HRMS m/z (ESI) Calcd for $\mathrm{C}_{28} \mathrm{H}_{45} \mathrm{NO}_{5} \mathrm{P}^{+}[\mathrm{M}+\mathrm{H}]^{+}$ 506.3030 Found: 506.3033. (RS/SR)-3d; pale yellow oil; $R_{\mathrm{f}}=0.67$ (EP/EtOAc 4:1); ${ }^{1} \mathrm{H}$ NMR (300 MHz, $\left.\mathrm{CDCl}_{3}\right) \delta 7.38(\mathrm{~m}, 5 \mathrm{H})$, $7.19(\mathrm{t}, J=7.8 \mathrm{~Hz}, 1 \mathrm{H}), 7.08(\mathrm{~m}, 2 \mathrm{H}), 6.85(\mathrm{~m}, 1 \mathrm{H}), 5.22(\mathrm{q}, J=$ $6.5 \mathrm{~Hz}, 1 \mathrm{H}), 5.07(\mathrm{~m}, 2 \mathrm{H}), 3.91(\mathrm{~m}, 2 \mathrm{H}), 3.45(\mathrm{~m}, 1 \mathrm{H}), 3.40(\mathrm{~d}$, $\left.J_{\mathrm{H}-\mathrm{P}}=26.1 \mathrm{~Hz}, 1 \mathrm{H}\right), 3.29(\mathrm{~m}, 1 \mathrm{H}), 1.54(\mathrm{~d}, J=6.6 \mathrm{~Hz}, 3 \mathrm{H}), 1.24$ (m, 6H), 1.21 (s, 9H), 1.19 (s, 9H), 0.91 (t, $J=7.1 \mathrm{~Hz}, 3 \mathrm{H}) .{ }^{31} \mathrm{P}$ NMR (121 MHz, $\left.\mathrm{CDCl}_{3}\right) \delta 24.65 .{ }^{13} \mathrm{C} \mathrm{NMR} \mathrm{(75} \mathrm{MHz}, \mathrm{CDCl}_{3}$ ) $\delta 158.5(\mathrm{C}), 145.1(\mathrm{C}), 137.3(\mathrm{C}), 128.9(\mathrm{CH}), 128.5(2 \times \mathrm{CH})$, $127.8(2 \times \mathrm{CH}), 127.4(\mathrm{CH}), 120.8(\mathrm{CH}), 114.1(\mathrm{CH}), 113.9(\mathrm{CH})$, $78.2(\mathrm{CH}), 70.1\left(\mathrm{CH}_{2}\right), 70.0\left(\mathrm{~d}, J_{\mathrm{C}-\mathrm{P}}=139.1 \mathrm{~Hz}, \mathrm{CH}\right), 61.6(\mathrm{~d}$, $\left.J_{\mathrm{C}-\mathrm{P}}=6.4 \mathrm{~Hz}, \mathrm{CH}_{2}\right), 61.3(\mathrm{C}), 58.7\left(\mathrm{~d}, J_{\mathrm{C}-\mathrm{P}}=7.5 \mathrm{~Hz}, \mathrm{CH}_{2}\right), 35.4$ $\left(\mathrm{d}, J_{\mathrm{C}-\mathrm{P}}=5.1 \mathrm{~Hz}, \mathrm{C}\right), 30.7\left(\mathrm{~d}, J_{\mathrm{C}-\mathrm{P}}=6.0 \mathrm{~Hz}, 3 \times \mathrm{CH}_{3}\right), 28.3(3 \times$
$\left.\mathrm{CH}_{3}\right), 21.3\left(\mathrm{CH}_{3}\right), 16.4\left(\mathrm{~d}, J_{\mathrm{C}-\mathrm{P}}=5.7 \mathrm{~Hz}, \mathrm{CH}_{3}\right), 16.2\left(\mathrm{~d}, J_{\mathrm{C}-\mathrm{P}}=6.9\right.$ $\mathrm{Hz}, \mathrm{CH}_{3}$ ). HRMS $m / z$ (ESI) Calcd for $\mathrm{C}_{28} \mathrm{H}_{45} \mathrm{NO}_{5} \mathrm{P}^{+}[\mathrm{M}+\mathrm{H}]^{+}$ 506.3030 Found: 506.3032.

Synthesis of 4-(1-((2,2,6,6-tetramethylpiperidin-1-yl)oxy) ethyl)phenol (1a). Alkoxyamines 1a was prepared according to the general procedure of hydrogenation using benzylated alkoxyamine 1b (300 mg, $0.544 \mathrm{mmol}, 1$ eq.) Alkoxyamine was purified by automatic flash column chromatography (petroleum ether/EtOAc; gradient: $100 \%$ to $60 \%$ ) to afford 1 a (86 mg, 57\%), pale orange oil; $R_{\mathrm{f}}=0.63(\mathrm{EP} /$ EtOAc $4: 1) ;{ }^{1} \mathrm{H}$ NMR (400 MHz, CDCl3) $\delta 7.11(\mathrm{~d}, J=7.7 \mathrm{~Hz}, 2 \mathrm{H}), 6.71(\mathrm{~d}, J=$ $7.8 \mathrm{~Hz}, 2 \mathrm{H}), 4.65$ (q, $J=6.7 \mathrm{~Hz}, 1 \mathrm{H}), 1.38(\mathrm{~d}, J=6.7 \mathrm{~Hz}, 3 \mathrm{H})$, 1.56-0.84 (m, 15H), $0.58(\mathrm{~s}, 3 \mathrm{H}) .{ }^{13} \mathrm{C}$ NMR (75 MHz, $\left.\mathrm{CDCl}_{3}\right)$ $\delta 154.5(\mathrm{C}), 136.8(\mathrm{C}), 127.4(2 \times \mathrm{CH}), 114.6(2 \times \mathrm{CH}), 81.8(\mathrm{CH})$, $59.0(2 \times \mathrm{C}), 39.7\left(2 \times \mathrm{CH}_{2}\right), 33.6\left(2 \times \mathrm{CH}_{3}\right), 22.5\left(\mathrm{CH}_{3}\right), 19.7(2 \times$ $\left.\mathrm{CH}_{3}\right), 16.6\left(\mathrm{CH}_{2}\right)$. HRMS $m / z$ (ESI) Calcd for $\mathrm{C}_{17} \mathrm{H}_{28} \mathrm{NO}_{2}{ }^{+}$ $[\mathrm{M}+\mathrm{H}]^{+}$278.2115 Found: 278.2115 .

Synthesis of 4-(1-((2,2,5,5-tetramethylpyrrolidin-1-yl)oxy) ethyl)phenol (2a). Alkoxyamines 2 a was prepared according to the general procedure of hydrogenation using benzylated alkoxyamine 2 b (200 mg, $0.566 \mathrm{mmol}, 1$ eq.) Alkoxyamine was purified by automatic flash column chromatography (petroleum ether/EtOAc; gradient: $100 \%$ to $60 \%$ ) to afford $2 \mathrm{a}$ (120 mg, 81\%), white solid; m.p.: $62{ }^{\circ} \mathrm{C} ; R_{\mathrm{f}}=0.73$ (EP/EtOAc $4: 1) ;{ }^{1} \mathrm{H}$ NMR (400 MHz, $\left.\mathrm{CDCl}_{3}\right) \delta 7.22(\mathrm{~d}, J=7.4 \mathrm{~Hz}, 2 \mathrm{H}), 6.78$ (d, $J=8.0 \mathrm{~Hz}, 2 \mathrm{H}), 4.60$ (q, $J=6.7 \mathrm{~Hz}, 1 \mathrm{H}), 1.56(\mathrm{~s}, 3 \mathrm{H}), 145$ (m, 1H), 1.44 (d, J = 6.6 Hz, 3H), 1.25 (s, 3H), 1.15 (s, 3H), 1.02 $(\mathrm{s}, 3 \mathrm{H}), 0.67$ (s, 3H). ${ }^{13} \mathrm{C} \mathrm{NMR}\left(75 \mathrm{MHz}, \mathrm{CDCl}_{3}\right) \delta 154.4$ (C), $137.1(\mathrm{C}), 128.3(2 \times \mathrm{CH}), 115.3(2 \times \mathrm{CH}), 81.5(\mathrm{CH}), 64.1(\mathrm{C})$, 63.0 (C), $35.9\left(\mathrm{CH}_{2}\right), 35.2\left(\mathrm{CH}_{2}\right), 31.0\left(\mathrm{CH}_{3}\right), 30.9\left(\mathrm{CH}_{3}\right), 24.1$ $\left(\mathrm{CH}_{3}\right), 22.7\left(\mathrm{CH}_{3}\right), 21.9\left(\mathrm{CH}_{3}\right)$. HRMS $\mathrm{m} / \mathrm{z}$ (ESI) Calcd for $\mathrm{C}_{16} \mathrm{H}_{25} \mathrm{NO}_{2}{ }^{+}[\mathrm{M}+\mathrm{H}]^{+}$264.1958 Found: 264.1956.

Synthesis of diethyl (1-(tert-butyl(1-(4-hydroxyphenyl)ethoxy) amino)-2,2-dimethylpropyl)phosphonate (3a). Alkoxyamines $(R R / S S)$-3a or $(R S / S R)$-3a was prepared according to the general procedure of hydrogenation using benzylated alkoxyamine $(R R / S S)-3 \mathbf{b}$ (200 mg, $0.396 \mathrm{mmol}, 1$ eq.) or $(R S / S R)-3 \mathbf{b}(200 \mathrm{mg}$, $0.396 \mathrm{mmol}, 1$ eq.) Alkoxyamines were purified by automatic flash column chromatography (petroleum ether/EtOAc; gradient: $100 \%$ to $40 \%)$ to afford $(R R / S S)-3 \mathrm{a}(125 \mathrm{mg}, 76 \%)$ or $(R R /$ $S S)$-3a (118 mg, 72\%). (RR/SS)-3a: white solid m.p.: $115{ }^{\circ} \mathrm{C}$ (decomp.); $R_{\mathrm{f}}=0.50$ (EP/EtOAc 3:2); ${ }^{1} \mathrm{H}$ NMR $(400 \mathrm{MHz}$, $\left.\mathrm{CDCl}_{3}\right) \delta 7.14(\mathrm{~d}, J=7.3 \mathrm{~Hz}, 2 \mathrm{H}), 6.86(\mathrm{~d}, J=8.5 \mathrm{~Hz}, 2 \mathrm{H}), 4.93$ $(\mathrm{q}, J=6.6 \mathrm{~Hz}, 1 \mathrm{H}), 4.37-4.18(\mathrm{~m}, 1 \mathrm{H}), 4.19-3.89(\mathrm{~m}, 3 \mathrm{H}), 3.37$ (d, $\left.J_{\mathrm{H}-\mathrm{P}}=26.4 \mathrm{~Hz}, 1 \mathrm{H}\right), 1.58(\mathrm{~d}, J=6.6 \mathrm{~Hz}, 3 \mathrm{H}), 1.29(\mathrm{~m}, 6 \mathrm{H})$, 1.25 (s, 9H), 0.88 (s, 9H). ${ }^{31} \mathrm{P}$ NMR (121 MHz, $\left.\mathrm{CDCl}_{3}\right) \delta 25.88$. ${ }^{13} \mathrm{C} \mathrm{NMR}\left(75 \mathrm{MHz}, \mathrm{CDCl}_{3}\right) \delta 156.3$ (C), 135.9 (C), $128.4(2 \times$ $\mathrm{CH}), 115.0(2 \times \mathrm{CH}), 84.3(\mathrm{CH}), 70.0\left(\mathrm{~d}, J_{\mathrm{C}-\mathrm{P}}=139.1 \mathrm{~Hz}, \mathrm{CH}\right)$, $61.9\left(\mathrm{~d}, J_{\mathrm{C}-\mathrm{P}}=6.3 \mathrm{~Hz}, \mathrm{CH}_{2}\right), 61.3(\mathrm{C}), 59.3\left(\mathrm{~d}, J_{\mathrm{C}-\mathrm{P}}=7.8 \mathrm{~Hz}\right.$, $\left.\mathrm{CH}_{2}\right), 35.6\left(\mathrm{~d}, J_{\mathrm{C}-\mathrm{P}}=5.5 \mathrm{~Hz}, \mathrm{C}\right), 30.2\left(\mathrm{~d}, J_{\mathrm{C}-\mathrm{P}}=5.9 \mathrm{~Hz}, 3 \times \mathrm{CH}_{3}\right)$, $28.5\left(3 \times \mathrm{CH}_{3}\right), 23.5\left(\mathrm{CH}_{3}\right), 16.5\left(\mathrm{~d}, J_{\mathrm{C}-\mathrm{P}}=5.9 \mathrm{~Hz}, \mathrm{CH}_{3}\right), 16.2(\mathrm{~d}$, $J_{\mathrm{C}-\mathrm{P}}=7.1 \mathrm{~Hz}, \mathrm{CH}_{3}$ ). HRMS $m / z$ (ESI) Calcd for $\mathrm{C}_{21} \mathrm{H}_{39} \mathrm{NO}_{5} \mathrm{P}^{+}$ $[\mathrm{M}+\mathrm{H}]^{+}$416.2560 Found: 416.2560. $(R S / S R)-3 \mathrm{a}$ : white solid m.p.: $115{ }^{\circ} \mathrm{C}$ (decomp.); $R_{\mathrm{f}}=0.70$ (EP/EtOAc $\left.3: 2\right) ;{ }^{1} \mathrm{H}$ NMR $\left(400 \mathrm{MHz}, \mathrm{CDCl}_{3}\right) \delta 7.18(\mathrm{~d}, J=8.5 \mathrm{~Hz}, 2 \mathrm{H}), 6.74(\mathrm{~d}, J=8.5 \mathrm{~Hz}$, $2 \mathrm{H}), 5.17(\mathrm{q}, J=6.5 \mathrm{~Hz}, 1 \mathrm{H}), 4.18-3.70(\mathrm{~m}, 3 \mathrm{H}), 3.50-3.45(\mathrm{~m}$, 
$1 \mathrm{H}), 3.47\left(\mathrm{~d}, J_{\mathrm{H}-\mathrm{P}}=26.6 \mathrm{~Hz}, 1 \mathrm{H}\right), 1.52(\mathrm{~d}, J=6.6 \mathrm{~Hz}, 3 \mathrm{H}), 1.23$ $(\mathrm{d}, J=2.4 \mathrm{~Hz}, 21 \mathrm{H}), 0.98(\mathrm{t}, J=7.1 \mathrm{~Hz}, 3 \mathrm{H}) .{ }^{31} \mathrm{P}$ NMR $(121 \mathrm{MHz}$, $\left.\mathrm{CDCl}_{3}\right) \delta 25.05 .{ }^{13} \mathrm{C} \mathrm{NMR}\left(75 \mathrm{MHz}, \mathrm{CDCl}_{3}\right) \delta 156.9$ (C), 133.6 (C), $128.7(2 \times \mathrm{CH}), 115.2(2 \times \mathrm{CH}), 78.5(\mathrm{CH}), 70.5\left(\mathrm{~d}, J_{\mathrm{C}-\mathrm{P}}=\right.$ $139.7 \mathrm{~Hz}, \mathrm{CH}), 62.5$ (d, $J_{\mathrm{C}-\mathrm{P}}=6.6 \mathrm{~Hz}, \mathrm{CH}_{2}$ ), $61.2(\mathrm{C}), 59.1$ (d, $\left.J_{\mathrm{C}-\mathrm{P}}=7.5 \mathrm{~Hz}, \mathrm{CH}_{2}\right), 35.4\left(\mathrm{~d}, J_{\mathrm{C}-\mathrm{P}}=5.2 \mathrm{~Hz}, \mathrm{C}\right), 30.8\left(\mathrm{~d}, J_{\mathrm{C}-\mathrm{P}}=\right.$ $\left.6.1 \mathrm{~Hz}, 3 \times \mathrm{CH}_{3}\right), 28.3\left(3 \times \mathrm{CH}_{3}\right), 21.6\left(\mathrm{CH}_{3}\right), 16.4\left(\mathrm{~d}, J_{\mathrm{C}-\mathrm{P}}=\right.$ $5.7 \mathrm{~Hz}, \mathrm{CH}_{3}$ ), 16.1 (d, $\left.J_{\mathrm{C}-\mathrm{P}}=7.1 \mathrm{~Hz}, \mathrm{CH}_{3}\right) . \mathrm{HRMS} \mathrm{m} / z$ (ESI) Calcd for $\mathrm{C}_{21} \mathrm{H}_{39} \mathrm{NO}_{5} \mathrm{P}^{+}[\mathrm{M}+\mathrm{H}]^{+}$416.2560 Found: 416.2558 .

Synthesis of diethyl(1-((1-hydroxy-2-methylpropan-2-yl)(1-(4hydroxyphenyl)ethoxy)amino)-2,2 dimethylpropyl)phosphonate (4a). Alkoxyamines $(R R / S S)$-4a or $(R S / S R)$-4a was prepared according to the general procedure of hydrogenation using benzylated alkoxyamine $(R R / S S)-4 \mathbf{b}(200 \mathrm{mg}, 0.373 \mathrm{mmol}$, 1 eq.) and (RS/SR)-4b (300 mg, $0.560 \mathrm{mmol}, 1$ eq.) Alkoxyamines were purified by automatic flash column chromatography (petroleum ether/EtOAc; gradient: $100 \%$ to $40 \%$ ) to afford $(R R / S S)-\mathbf{4 a}(127 \mathrm{mg}, 79 \%)$ or $(R R / S S)-\mathbf{4 a}(185 \mathrm{mg}, 77 \%)$. $(R R / S S)$-4a: white solid m.p.: $115{ }^{\circ} \mathrm{C}$ (decomp.); $R_{\mathrm{f}}=0.30(\mathrm{EP} /$ EtOAc $1: 1) ;{ }^{1} \mathrm{H}$ NMR (400 MHz, $\left.\mathrm{CDCl}_{3}\right) \delta 7.12$ (d, $J=8.0 \mathrm{~Hz}$, $2 \mathrm{H}), 6.75$ (d, $J=8.2 \mathrm{~Hz}, 2 \mathrm{H}), 4.80$ (q, $J=6.5 \mathrm{~Hz}, 1 \mathrm{H}), 4.37-3.91$ $(\mathrm{m}, 5 \mathrm{H}), 3.55\left(\mathrm{~d}, J_{\mathrm{H}-\mathrm{P}}=26.6 \mathrm{~Hz}, 1 \mathrm{H}\right), 3.39(\mathrm{~d}, J=12.1 \mathrm{~Hz}, 1 \mathrm{H})$, $3.10(\mathrm{~d}, J=12.1 \mathrm{~Hz}, 1 \mathrm{H}), 1.46(\mathrm{~d}, J=6.6 \mathrm{~Hz}, 2 \mathrm{H}), 1.27(\mathrm{~m}, 6 \mathrm{H})$, $1.15(\mathrm{~s}, 9 \mathrm{H}), 0.97(\mathrm{~s}, 3 \mathrm{H}), 0.78(\mathrm{~s}, 3 \mathrm{H}) .{ }^{31} \mathrm{P}$ NMR $(162 \mathrm{MHz}$, $\left.\mathrm{CDCl}_{3}\right) \delta 27.06 .{ }^{13} \mathrm{C} \mathrm{NMR}\left(101 \mathrm{MHz}, \mathrm{CDCl}_{3}\right) \delta 156.5$ (C), 135.5 (C), $127.9(2 \times \mathrm{CH}), 115.2(2 \times \mathrm{CH}), 84.5(\mathrm{CH}), 69.6\left(\mathrm{~d}, J_{\mathrm{C}-\mathrm{P}}=\right.$ $136.4 \mathrm{~Hz}, \mathrm{CH}), 67.4\left(\mathrm{CH}_{2}\right), 64.8(\mathrm{C}), 62.0\left(\mathrm{~d}, J_{\mathrm{C}-\mathrm{P}}=6.6 \mathrm{~Hz}, \mathrm{CH}_{2}\right)$, $60.8\left(\mathrm{~d}, J_{\mathrm{C}-\mathrm{P}}=8.0 \mathrm{~Hz}, \mathrm{CH}_{2}\right), 35.7\left(\mathrm{~d}, J_{\mathrm{C}-\mathrm{P}}=4.5 \mathrm{~Hz}, \mathrm{C}\right), 30.1$ (d, $\left.J_{\mathrm{C}-\mathrm{P}}=5.6 \mathrm{~Hz}, 3 \times \mathrm{CH}_{3}\right), 26.8\left(\mathrm{CH}_{3}\right), 24.1\left(\mathrm{CH}_{3}\right), 23.2\left(\mathrm{CH}_{3}\right), 16.5$ $\left(\mathrm{d}, J_{\mathrm{C}-\mathrm{P}}=5.8 \mathrm{~Hz}, \mathrm{CH}_{3}\right), 16.2\left(\mathrm{~d}, J_{\mathrm{C}-\mathrm{P}}=6.8 \mathrm{~Hz}, \mathrm{CH}_{3}\right) .(R S / S R)-4 \mathrm{a}$ : white solid m.p.: $115^{\circ} \mathrm{C}$ (decomp.); $R_{\mathrm{f}}=0.45$ (EP/EtOAc $\left.1: 1\right)$; ${ }^{1} \mathrm{H}$ NMR (400 MHz, $\left.\mathrm{CDCl}_{3}\right) \delta 9.01(\mathrm{~s}, 1 \mathrm{H}), 7.24(\mathrm{~d}, J=8.1 \mathrm{~Hz}$, $2 \mathrm{H}), 6.79$ (d, $J=8.2 \mathrm{~Hz}, 2 \mathrm{H}), 5.11$ (q, $J=6.5 \mathrm{~Hz}, 1 \mathrm{H}), 4.51(\mathrm{~s}$, $1 \mathrm{H}), 4.01-3.64(\mathrm{~m}, 6 \mathrm{H}), 3.79\left(\mathrm{~d}, J_{\mathrm{H}-\mathrm{P}}=26.6 \mathrm{~Hz}, 1 \mathrm{H}\right), 1.55(\mathrm{~d}, J=$ $6.5 \mathrm{~Hz}, 3 \mathrm{H}), 1.33(\mathrm{~s}, 3 \mathrm{H}), 1.28-1.04(\mathrm{~m}, 18 \mathrm{H}) .{ }^{31} \mathrm{P}$ NMR $\left(162 \mathrm{MHz}, \mathrm{CDCl}_{3}\right) \delta 26.30 .{ }^{13} \mathrm{C} \mathrm{NMR}\left(101 \mathrm{MHz}, \mathrm{CDCl}_{3}\right) \delta 156.7$ (C), $133.6(\mathrm{C}), 127.8(2 \times \mathrm{CH}), 115.1(2 \times \mathrm{CH}), 78.2(\mathrm{CH}), 70.1$ $\left(\mathrm{d}, J_{\mathrm{C}-\mathrm{P}}=136.7 \mathrm{~Hz}, \mathrm{CH}\right), 68.2\left(\mathrm{CH}_{2}\right), 64.4(\mathrm{C}), 62.5\left(\mathrm{~d}, J_{\mathrm{C}-\mathrm{P}}=6.6\right.$ $\mathrm{Hz}, \mathrm{CH}_{2}$ ), 60.7 (d, $\left.J_{\mathrm{C}-\mathrm{P}}=8.0 \mathrm{~Hz}, \mathrm{CH}_{2}\right), 35.4\left(\mathrm{~d}, J_{\mathrm{C}-\mathrm{P}}=4.4 \mathrm{~Hz}, \mathrm{C}\right)$, $30.5\left(\mathrm{~d}, J_{\mathrm{C}-\mathrm{P}}=5.8 \mathrm{~Hz} 3 \times \mathrm{CH}_{3}\right), 26.2\left(\mathrm{CH}_{3}\right), 23.9\left(\mathrm{CH}_{3}\right), 21.7$ $\left(\mathrm{CH}_{3}\right), 16.3\left(\mathrm{~d}, J_{\mathrm{C}-\mathrm{P}}=5.8 \mathrm{~Hz}, \mathrm{CH}_{3}\right), 16.0\left(\mathrm{~d}, J_{\mathrm{C}-\mathrm{P}}=6.9 \mathrm{~Hz}, \mathrm{CH}_{3}\right)$. HRMS $m / z$ (ESI) Calcd for $\mathrm{C}_{21} \mathrm{H}_{39} \mathrm{NO}_{6} \mathrm{P}^{+}[\mathrm{M}+\mathrm{H}]^{+} 432.2510$ Found: 432.2507 (for a mixture of diastereoisomers).

Synthesis of 4-(1-((di-tert-butylamino)oxy)ethyl)phenol (5a). Alkoxyamines 5a was prepared according to the general procedure of hydrogenation using benzylated alkoxyamine $\mathbf{5 b}$ ( $250 \mathrm{mg}, 0.703 \mathrm{mmol}, 1 \mathrm{eq}$.) Alkoxyamine was purified by automatic flash column chromatography (petroleum ether/EtOAc; gradient: $100 \%$ to $60 \%$ ) to afford 5 a (91 $\mathrm{mg}, 49 \%$ ), pale orange oil; $R_{\mathrm{f}}=0.58$ (EP/EtOAc 4:1); HRMS $\mathrm{m} / z$ (ESI) Calcd for $\mathrm{C}_{16} \mathrm{H}_{28} \mathrm{NO}_{2}^{+}[\mathrm{M}+\mathrm{H}]^{+}$266.2115 Found: 266.2114.

Synthesis of diethyl (1-(tert-butyl(1-(3-hydroxyphenyl)ethoxy) amino)-2,2-dimethylpropyl)phosphonate (3e). Alkoxyamines $(R R / S S)$-3e or $(R S / S R)-3 \mathbf{e}$ was prepared according to the general procedure of hydrogenation using benzylated alkoxyamine $(R R / S S)$-3d (90 mg, $0.178 \mathrm{mmol}, 1$ eq.) or $(R S / S R)-3 \mathbf{d}(150 \mathrm{mg}$,
$0.297 \mathrm{mmol}, 1$ eq.) Alkoxyamines were purified by automatic flash column chromatography (petroleum ether/EtOAc; gradient: $100 \%$ to $40 \%)$ to afford $(R R / S S)-3$ e $(53 \mathrm{mg}, 71 \%)$ or $(R R /$ $S S)$-3e (95 mg, 77\%). (RR/SS)-3e: white solid m.p.: $115{ }^{\circ} \mathrm{C}$ (decomp.); $R_{\mathrm{f}}=0.50$ (EP/EtOAc $\left.3: 2\right) ;{ }^{1} \mathrm{H}$ NMR $(400 \mathrm{MHz}$, $\left.\mathrm{CDCl}_{3}\right) \delta 8.31(\mathrm{~s}, 1 \mathrm{H}), 7.04(\mathrm{t}, J=7.7 \mathrm{~Hz}, 1 \mathrm{H}), 6.83(\mathrm{~s}, 1 \mathrm{H}), 6.71$ (t, $J=7.1 \mathrm{~Hz}, 2 \mathrm{H}), 4.85(\mathrm{q}, J=6.5 \mathrm{~Hz}, 1 \mathrm{H}), 4.25(\mathrm{~m}, 1 \mathrm{H}), 4.00$ $(\mathrm{m}, 3 \mathrm{H}), 3.30\left(\mathrm{~d}, J_{\mathrm{H}-\mathrm{P}}=26.1 \mathrm{~Hz}, 1 \mathrm{H}\right), 1.50(\mathrm{~d}, J=6.7 \mathrm{~Hz}, 3 \mathrm{H})$, $1.23(\mathrm{~m}, 6 \mathrm{H}), 1.17$ (s, 9H), 0.83 (s, 9H). ${ }^{31} \mathrm{P}$ NMR (121 MHz, $\left.\mathrm{CDCl}_{3}\right) \delta 26.14 .{ }^{13} \mathrm{C} \mathrm{NMR}\left(101 \mathrm{MHz}, \mathrm{CDCl}_{3}\right) \delta 156.8(\mathrm{C}), 146.8$ (C), $129.0(\mathrm{CH}), 118.3(\mathrm{CH}), 114.2(\mathrm{CH}), 114.2(\mathrm{CH}), 85.5(\mathrm{CH})$, $70.0\left(\mathrm{~d}, J_{\mathrm{C}-\mathrm{P}}=138.7 \mathrm{~Hz}, \mathrm{CH}\right), 62.1\left(\mathrm{~d}, J_{\mathrm{C}-\mathrm{P}}=6.4 \mathrm{~Hz}, \mathrm{CH}_{2}\right), 61.4$ (C), $59.3\left(\mathrm{~d}, J_{\mathrm{C}-\mathrm{P}}=7.5 \mathrm{~Hz}, \mathrm{CH}_{2}\right.$ ), 35.7 (d, $\left.J_{\mathrm{C}-\mathrm{P}}=5.7 \mathrm{~Hz}, \mathrm{C}\right), 30.0$ $\left(\mathrm{d}, J_{\mathrm{C}-\mathrm{P}}=5.7 \mathrm{~Hz}, 3 \times \mathrm{CH}_{3}\right), 28.6\left(3 \times \mathrm{CH}_{3}\right), 24.2\left(\mathrm{CH}_{3}\right), 16.7(\mathrm{~d}$, $\left.J_{\mathrm{C}-\mathrm{P}}=5.6 \mathrm{~Hz}, \mathrm{CH}_{3}\right), 16.2\left(\mathrm{~d}, J_{\mathrm{C}-\mathrm{P}}=6.9 \mathrm{~Hz}, \mathrm{CH}_{3}\right) . \mathrm{HRMS} \mathrm{m} / \mathrm{z}$ (ESI) Calcd for $\mathrm{C}_{21} \mathrm{H}_{39} \mathrm{NO}_{5} \mathrm{P}^{+}[\mathrm{M}+\mathrm{H}]^{+} 416.2560$ Found: 416.2562. (RS/SR)-3e: white solid m.p.: $115^{\circ} \mathrm{C}$ (decomp.); $R_{\mathrm{f}}=$ 0.70 (EP/EtOAc $3: 2) ;{ }^{1} \mathrm{H}$ NMR (400 $\left.\mathrm{MHz}, \mathrm{CDCl}_{3}\right) \delta{ }^{1} \mathrm{H} \mathrm{NMR}$ $\left(400 \mathrm{MHz}, \mathrm{CDCl}_{3}\right) \delta 8.73(\mathrm{~s}, 1 \mathrm{H}), 7.10(\mathrm{t}, J=7.8 \mathrm{~Hz}, 1 \mathrm{H}), 7.03(\mathrm{~s}$, $1 \mathrm{H}), 6.94(\mathrm{~d}, J=7.6 \mathrm{~Hz}, 1 \mathrm{H}), 6.74(\mathrm{dd}, J=8.0,1.6 \mathrm{~Hz}, 2 \mathrm{H}), 5.17$ $(\mathrm{q}, J=6.5 \mathrm{~Hz}, 1 \mathrm{H}), 3.91(\mathrm{~m}, 2 \mathrm{H}), 3.56(\mathrm{~m}, 2 \mathrm{H}), 3.44\left(\mathrm{~d}, J_{\mathrm{H}-\mathrm{P}}=\right.$ $26.3 \mathrm{~Hz}, 1 \mathrm{H}), 1.53(\mathrm{~d}, J=6.5 \mathrm{~Hz}, 3 \mathrm{H}), 1.22(\mathrm{~m}, 21 \mathrm{H}), 0.97(\mathrm{t}, J=$ $7.1 \mathrm{~Hz}, 3 \mathrm{H}) .{ }^{31} \mathrm{P}$ NMR (121 MHz, $\left.\mathrm{CDCl}_{3}\right) \delta 24.97{ }^{13} \mathrm{C} \mathrm{NMR}$ $\left(101 \mathrm{MHz}, \mathrm{CDCl}_{3}\right) \delta 156.9(\mathrm{C}), 144.7(\mathrm{C}), 128.9(\mathrm{CH}), 117.9$ $(\mathrm{CH}), 115.3(\mathrm{CH}), 114.5(\mathrm{CH}), 78.7(\mathrm{CH}), 70.3(\mathrm{~d}, J=139.5 \mathrm{~Hz}$, $\mathrm{CH}), 62.4$ (d, $J=6.5 \mathrm{~Hz}, \mathrm{CH}_{2}$ ), $61.4(\mathrm{C}), 59.1$ (d, $J=7.6 \mathrm{~Hz}$, $\left.\mathrm{CH}_{2}\right), 35.5(\mathrm{~d}, J=5.1 \mathrm{~Hz}, \mathrm{C}), 30.6\left(\mathrm{~d}, J=6.0 \mathrm{~Hz}, 3 \times \mathrm{CH}_{3}\right), 28.3$ $\left(3 \times \mathrm{CH}_{3}\right), 21.66\left(\mathrm{CH}_{3}\right), 16.40\left(\mathrm{~d}, J=5.8 \mathrm{~Hz}, \mathrm{CH}_{3}\right), 16.08(\mathrm{~d}, J=$ $7.2 \mathrm{~Hz}, \mathrm{CH}_{3}$ ). HRMS m/z (ESI) Calcd for $\mathrm{C}_{21} \mathrm{H}_{39} \mathrm{NO}_{5} \mathrm{P}^{+}[\mathrm{M}+\mathrm{H}]^{+}$ 416.2560 Found: 416.2561.

\section{Chemical oxidation as trigger}

Addition of several equivalents of lead dioxide $\mathrm{PbO}_{2}$ to a $0.1 \mathrm{mM}$ solution of alkoxyamines $\mathbf{1 a}-\mathbf{5 a}$, and after a vigorous 20 seconds hand-shaking, provides an EPR signal. Then, using this procedure, effect of 10 equivalents to 1500 equivalents of $\mathrm{PbO}_{2}$ on alkoxyamines 1a-5a was tested (ESI Table $1 \dagger$ ). Nitroxides $4^{\circ}$ and $5^{\circ}$ are not stable in the presence of $\mathrm{PbO}_{2}$, presumably due to further oxidation to oxoamoniums, impeding the growth of significant EPR signals upon oxidation of the corresponding alkoxyamines (only a few percent of conversion were detected). For low amounts of $\mathrm{PbO}_{2}$, more vigorous handshakings do not increase the amount of released nitroxide.

\section{CIDNP experiments}

${ }^{1} \mathrm{H}$ NMR and CIDNP spectra were recorded on a $200 \mathrm{MHz}$ Bruker AVANCE DPX spectrometer. In situ irradiation of samples inside NMR magnet was carried out by using a frequency-tripled Quantel Brilliant B Nd:YAG laser (355 nm, 8 ns, ca. $70 \mathrm{~mJ}$ per pulse) The following pulse sequence was used: presaturation (laser flash)-(RF)-(detection pulse, 2 us)-(free induction decay). Dark spectra (without the laser flash) were always recorded as a reference for a proper suppression of the background NMR transitions.

Deuterated solvents were purchased from Sigma-Aldrich and used without additional treatment. All the samples were 
deaerated by bubbling with $\mathrm{N}_{2}$ for 5 minutes prior to the CIDNP experiment.

\section{DFT calculations}

All calculations were performed using the Gaussian 16 electronic structure package ${ }^{55}$ at the M06-2X/6-31+G(d,p) level of theory, ${ }^{53}$ and the nature of all stationary points confirmed with frequency calculations at the same level. Gas-phase Gibbs free energies at $298.15 \mathrm{~K}$ were calculated using standard textbook formulae based upon the statistical thermodynamics of an ideal gas under the harmonic oscillator and rigid-rotor approximations. Solvent corrections were obtained with the SMD continuum solvent model for methanol, ${ }^{56}$ and the thermocycle approach was employed to determine Gibbs free energies in solution. ${ }^{57}$ All energies given are from conformationally-searched and Boltzmann-weighted conformer distributions.

\section{HPLC measurements and mass spectral analyses}

Alkoxyamines and their homolysed products were separated and monitored by HPLC using an Agilent 1260 apparatus equipped with a UV-Vis absorption and MS detector. Typically, $1 \mu \mathrm{l}$ of a sample was injected on C18 column (Phenomenex, Luna Omega Polar $1.6 \mu \mathrm{m}, 100 \times 2.1 \mathrm{~mm}$ ) equilibrated with acetonitrile/water mobile phase $(15 / 85 \mathrm{v} / \mathrm{v})$ containing $0.1 \%$ formic acid. Compounds were separated by a linear increased of the acetonitrile concentration from 15 to $100 \%$ over $8 \mathrm{~min}$. Next, the concentration of acetonitrile was kept at this level for $13 \mathrm{~min}$. All analytes, were eluted at a flow rate of $0.14 \mathrm{ml}$ $\mathrm{min}^{-1}$. The absorption traces were collected at $230 \mathrm{~nm}$. The structural identity of products was confirmed by MS analysis using an Agilent 6120 quadrupole mass spectrometer equipped with electrospray ion source. The compounds were detected in the positive-ion mode.

\section{Kinetic measurements}

Rate constants $k_{\mathrm{d}}$ for the homolysis of the $\mathrm{C}-\mathrm{ON}$ bond of alkoxyamines $\mathbf{1 a}, \mathbf{b}-\mathbf{5 a}, \mathbf{b}$ (Scheme 7) are determined using eqn (2) and by monitoring the growth of nitroxide by EPR, using $\mathrm{O}_{2}$ as alkyl radical scavenger as previously reported. ${ }^{58}$ For all alkoxyamines, a plateau in nitroxides is reached for more than $90 \%$ conversion at any temperatures. For the sake of simplicity, activation energies $E_{\mathrm{a}}$ are estimated using the Arrhenius equation in conjunction with the averaged frequency factor $A=$ $2.410^{14} \mathrm{~s}^{-1}$. ${ }^{34}$ For ease of discussion, values of $k_{\mathrm{d}}^{\prime}$ at $120{ }^{\circ} \mathrm{C}$ are obtained from the Arrhenius equation, and half lives $\left(t_{1 / 2}\right)$

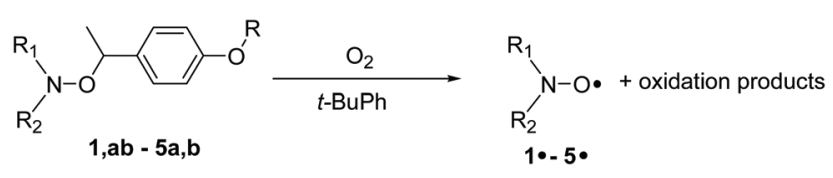

Scheme 7 Thermal homolysis of $1 a, b-5 a, b$ in $t-B u P h$ in the presence of $\mathrm{O}_{2}$ as scavenger at various temperatures. are obtained assuming first order kinetics. All data are gathered in Table 1.

$$
\ln \frac{[\text { nitroxide }]_{\infty}-[\text { nitroxide }]_{t}}{[\text { nitroxide }]_{\infty}}=-k_{\mathrm{d}} \cdot t
$$

\section{Conclusions}

Oxidation of bench stable alkoxyamines yields highly reactive intermediates capable of undergoing $\mathrm{S}_{\mathrm{N}} 2$ reactions with nucleophiles and/or mesolytic cleavage to form carbon-centred radicals or carbocations for use in chemical synthesis. To date electrochemical and photoredox methods have been used for this purpose; in this contribution we show that chemical oxidation provides a mild and convenient alternative. Moreover, when the nitroxide bears phenolic leaving groups we show that alkoxyamine cleavage can also be triggered by proton coupled electron transfer followed by a $\beta$-fragmentation reaction to afford methine quinone like-compounds. Both processes have potential to expand the scope of smart alkoxyamines in chemical synthesis, and as reporter molecules of oxidising environments.

\section{Author contributions}

All authors contribute equally.

\section{Conflicts of interest}

There are no conflicts to declare.

\section{Acknowledgements}

SRAM, MH and GA are thankful to Aix-Marseille University and CNRS for support. $\mathrm{JH}$ and $\mathrm{MH}$ are grateful to ANR for support (ANR-17-CE18-0017 and ANR-15-CE18-0012-01). SJ and EV thank Ministry for support. TMMK thank Campus France and government of Gabon for support. MLC gratefully acknowledges generous allocations of supercomputing time on the National Facility of the National Computational Infrastructure and an Australian Research Council Laureate Fellowship (FL170100041).

\section{Notes and references}

1 G. Audran, P. Brémond, J.-M. Franconi, S. R. A. Marque, P. Massot, P. Mellet, E. Parzy and E. Thiaudière, Alkoxyamines: a New Family of Pro-Drugs against Cancer. Concept for Theranostics, Org. Biomol. Chem., 2014, 12, 719.

2 P. Brémond, A. Koïta, S. R. A. Marque, V. Pesce, V. Roubaud and D. Siri, Chemically Trigerred C-ON Bond Homolysis of 
Alkoxyamines. Quaternization of the Alkyl Fragments, Org. Lett., 2012, 14(1), 358.

3 G. Audran, E. Bagryanskaya, I. Bagryanskaya, P. Brémond, M. Edeleva, S. R. A. Marque, D. Parkhomenko, E. Tretyakov and S. Zhivetyeva, C-ON Bond Homolysis of Alkoxyamines Triggered by Paramagnetic Copper(II) Salts, Inorg. Chem. Front., 2016, 3(11), 1464.

4 G. Gryn'ova, D. L. Marshall, S. J. Blanksby and M. L. Coote, Switching Radical Stability by $\mathrm{pH}$-Induced Orbital Conversion, Nat. Chem., 2013, 5, 474.

5 G. Gryn'ova, L. M. Smith and M. L. Coote, Computational design of $\mathrm{pH}$-switchable control agents for nitroxide mediated polymerization, Phys. Chem. Chem. Phys., 2017, 19, 22678-22683.

6 Y. Guillaneuf, D.-L. Versace, D. Bertin, J. Lalevée, D. Gigmes and J.-P. Fouassier, Importance of the Position of the Chromophore Group on the Dissociation Process of Light Sensitive Alkoxyamine, Macromol. Rapid Commun., 2010, 31, 1909-1913.

7 Y. Guillaneuf, D. Bertin, D. Gigmes, D.-L. Versace, J. Lalevée and J.-P. Fouassier, Toward Nitroxide-Mediated Photopolymerization, Macromolecules, 2010, 43, 2204.

8 J. Morris, S. Telitel, K. E. Fairfull-Smith, S. E. Bottle, J. Lalevée, J.-L. Clément, Y. Guillaneuf and D. Gigmes, Novel polymer synthesis methodologies using combinations of thermally- and photochemically-induced nitroxide Mediated Polymerization, Polym. Chem., 2015, 6, 754763.

9 S. E. Bottle, J.-L. Clement, M. Fleige, E. M. Simpson, Y. Guillaneuf, K. E. Fairfull-Smith, D. Gigmes and J. P. Blinco, Light-Active Azaphenalene Alkoxyamines: Fast and Efficient Mediators of a Photo-Induced Persistent Radical Effect, RSC Adv., 2016, 6, 80328-80333.

10 G. Audran, L. Bosco, P. Brémond, N. Jugniot, S. R. A. Marque, P. Massot, P. Mellet, T. Moussounda Moussounda Koumba, E. Parzy, A. Rivot, E. Thiaudière, P. Voisin, C. Wedl and T. Yamasaki, Controlled Radical Initiation Triggered by Specific Enzymatic Activity, Org. Chem. Front., 2019, 6, 3663.

11 M. Albalat, G. Audran, M. Holzritter, S. R. A. Marque, P. Mellet, N. Vanthuyne and P. Voisin, An Enzymatic Acetal/Hemiacetal Conversion for the Physiological Temperature Activation of the Alkoxyamine $\mathrm{C}-\mathrm{ON}$ Bond Homolysis, Org. Chem. Front., 2020, 7, 2916.

12 M. Edeleva, D. Morozov, D. Parkhomenko, Y. Polienko, A. Iurchenkova, I. Kirilyuk and E. G. Bagryanskaya, Versatile approach to activation of alkoxyamine homolysis by 1,3-dipolar cycloaddition for efficient and safe nitroxide mediated polymerization, Chem. Commun., 2019, 55, 190.

13 D. Moncelet, P. Voisin, N. Koonjoo, V. Bouchaud, P. Massot, E. Parzy, G. Audran, J.-M. Franconi, E. Thiaudière, S. R. A. Marque, P. Brémond and P. Mellet, Alkoxyamines: Towards a New Family of Theranostic Agents Against Cancer, Mol. Pharmaceutics, 2014, 11, 2412.

14 T. Yamasaki, D. Buric, Ch. Chacon, G. Audran, D. Braguer, S. R. A. Marque, M. Carré and P. Brémond, Chemical modi- fications of imidazole-containing alkoxyamines increase CON bond homolysis rate: effects on cytotoxic properties in glioblastoma cells, Bioorg. Med. Chem., 2019, 27, 1942.

15 A. Yamada, M. Abe, Y. Nishimura, S. Ishizaka, M. Namba, T. Nakashima, K. Shimoji and N. Hattori, Photochemical generation of the 2,2,6,6-tetramethylpiperidine-1-oxyl (TEMPO radical from, caged nitroxides by near-infrared two-photon irradiation and its cytocidal effect on lung cancer cells, Beilstein J. Org. Chem., 2019, 15, 863.

16 L. Tebben and A. Studer, Nitroxide: Applications in Synthesis and in Polymer Chemistry, Angew. Chem., Int. Ed., 2011, 50, 5034.

17 J. E. Nutting, M. Rafiee and S. S. Stahl, Tertamethylpiperidine N-oxyl (TEMPO)Phtalimide N-Oxyl (PINO), and Related N-Oxyl Species: Electrochemical Properties and Their Use in Electrocatalytic Reactions, Chem. Rev., 2018, 118, 4834.

18 T. Reyser, H. To, C. Egwu, L. Paloque, M. Nguyen, A. Hamouy, J.-L. Stigliani, C. Bijani, J.-M. Augereau, J.-P. Joly, J. Portela, J. Havot, S. R. A. Marque, J. Boissier, A. Robert, F. Benoit-Vical and G. Audran, Alkoxyamines Designed as Potential Drugs Against Plasmodium and Schistosoma Parasites, Molecules, 2020, e3838.

19 B. B. Noble, P. L. Norcott, C. L. Hammill, S. Ciampi and M. L. Coote, Mechanism of Oxidative Alkoxyamine Cleavage: the Surprising Role of the Solvent and Supporting Electrolyte, J. Phys. Chem. C, 2019, 123, 1030010305.

20 C. L. Hammill, B. B. Noble, P. L. Norcott, S. Ciampi and M. L. Coote, Effect of Chemical Structure on the Electrochemical Cleavage of Alkoxyamines, J. Phys. Chem. C, 2019, 123, 5273.

21 P. L. Norcott, C. L. Hammill, B. B. Noble, J. C. Robertson, A. Olding, A. C. Bissember and M. L. Coote, TEMPO-Me: an Electrochemically Activated Methylating Agent, J. Am. Chem. Soc., 2019, 141, 15450-15455.

22 F. J. M. Rogers, B. B. Noble and M. L. Coote, Computational optimization of alkoxyamine-based electrochemical methylation, J. Phys. Chem. A, 2020, 124, 6104-6110.

23 L. Zhang, E. Laborda, N. Darwish, B. B. Noble, J. H. Tyrell, S. Pluczyk, A. P. Le Brun, G. G. Wallace, J. Gonzalez, M. L. Coote and S. Ciampi, Electrochemical and Electrostatic Cleavage of Alkoxyamines, J. Am. Chem. Soc., 2018, 140, 766.

24 Q. Zhu, E. C. Gentry and R. R. Knowles, Catalytic ncarbocation Generation Enabled nby the Mesolyticn Cleavage of Alkoxyamine radical Cation, Angew. Chem., Int. Ed., 2016, 55, 9969.

25 E. C. Gentry, L. J. Rono, M. E. Hale, R. Matsuura and R. R. Knowles, Enantioselective Synthesis of Pyrroloindolines via Noncovalent Stabilization of Indole Radical Cations and Applications to the Synthesis of Alkaloid Natural Products, J. Am. Chem. Soc., 2018, 140(9), 3394.

26 N. S. Hill, M. J. Fule, J. Morris, J.-L. Clément, Y. Guillaneuf, D. Gigmes and M. L. Coote, Mesolytic versus homolytic 
cleavage in photochemical nitroxide mediated polymerization, Macromolecules, 2020, 53, 1567-1572.

27 D. R. Weinberg, C. J. Gagliardi, J. F. Hull, C. F. Murphy, C. A. Kent, B. C. Westlake, A. Paul, D. H. Ess, D. G. McCafferty and T. J. Meyer, Proton-coupled electron transfer, Chem. Rev., 2012, 112, 4016.

28 J. B. Shotwell, E. S. Krygowski, J. Hines, B. Koh, E. W. D. Huntsman, H. W. Choi, J. S. Schneekloth Jr., J. L. Wood and C. M. Crews, Total synthesis of the antiangiogenic agent Luminacin D, Org. Lett., 2002, 18, 3087.

29 J. Dao, D. Benoît and C. J. Hawker, A Versatile and Efficient Synthesis of Alkoxyamine LFR Initiators via Manganese Based Asymmetric Epoxidation Catalysts, J. Polym. Sci., Part A: Polym. Chem., 1998, 36, 2161.

30 D. Bertin, D. Gigmes, S. R. A. Marque and P. Tordo, Polar, Steric, and Stabilization Effects in Alkoxyamines C-ON Bond Homolysis: A Multiparameters Analysis, Macromolecules, 2005, 38(7), 2638.

31 H. Fischer, A. Kramer, S. R. A. Marque and P. Nesvadba, Steric and Polar Effects of the Cyclic Nitroxyl Fragment on the C-ON Bond Homolysis Rate Constant, Macromolecules, 2005, 38(24), 9974.

32 C. Y. Lin, S. R. A. Marque, K. Matyjaszewski and M. L. Coote, Linear-Free energy relationships for modeling structure-reactivity trends in Controlled Radical Polymerization, Macromolecules, 2011, 44(19), 7568-7583.

33 J. L. Hodgson, C.-Y. Lin, M. L. Coote, S. R. A. Marque and K. Matyjaszewski, Linear Free Energy Relationship for the Alkyl Affinities of Nitroxides: A Theoretical Study, Macromolecules, 2010, 43(8), 3728.

34 S. Marque, The influence of the nitroxide structure on homolysis rate of alkoxyamines: A Taft-Ingold analysis, J. Org. Chem., 2003, 68(20), 7582.

35 E. G. Bagryanskaya and S. R. A. Marque, Kinetic Aspects of Nitroxide-Mediated Polymerization, in Nitroxide Mediated Polymerization: From Fundamentals to Applications in Materials Sciences, RSC Polymer Chemistry Series, $\mathrm{n}^{\circ}=19$, ed. D. Gigmes, Royal Society of Chemistry, 2016, ch. 2, pp. 45-113.

36 G. Gryn'ova, K. U. Ingold and M. L. Coote, New insights into the mechanism of amine/nitroxide cycling during the hindered amine light stabilizer inhibited oxidativen degradation of polymers, J. Am. Chem. Soc., 2012, 134, 1297912988.

37 S. Marque, H. Fischer, E. Baier and A. Studer, Factors influencing the C-O-bond homolysis of alkoxyamines: Effect of H-bonding and polar substituents, J. Org. Chem., 2001, 66(4), 1146.

38 G. Audran, P. Brémond, J.-P. Joly, S. R. A. Marque and T. Yamasaki, C-ON bond homolysis of alkoxyamines. Part 12: Effect of the para-substituent in the 1-phenylethyl fragment, Org. Biomol. Chem., 2016, 14, 3574.

39 C. Hansch, A. Leo and R. W. Taft, A Survey of Hammett substituent constants and resonance and field parameters, Chem. Rev., 1991, 91, 165.

40 M. Charton, Adv. Mol. Struct. Res., 1999, 5, 25.
41 D. Bertin, D. Gigmes, S. R. A. Marque, S. Milardo, J. Peri and P. Tordo, Long-range polar effect on the C-ON bond homolysis in SG1 (N-(2-Methyl-2-propyl)-N-(1-diethylphosphono-2,2-dimethylpropyl)-N-oxyl) - alkoxyamines, Collect. Czech. Chem. Commun., 2004, 69(12), 2223.

42 G. Audran, S. Dorey, N. Dupuy, F. Gaston and S. R. A. Marque, Degradation of g-Irradiated Polyethyleneetylene Vinyl Alcohol-polyethylene Multilayer Films: An ESR Study, Polym. Degrad. Stab., 2015, 122, 169.

43 D. Griller and K. U. Ingold, Electron paramagnetic resonance and the art of physical-organic chemistry, Acc. Chem. Res., 1980, 13(7), 193.

44 J. J. Henderson, Concerning the relationship between the strength of acids and their capacity to preserve neutrality, Am. J. Physiol., 1908, 21, 173.

45 G. L. Closs and R. J. Miller, Gas-ohase basicities of amides and imidates. Estgim tion of protomeric equilibrium constants by the basicity method in the gas phase, J. Am. Chem. Soc., 1979, 101(6), 1639.

46 J.-K. Vollenweider, H. Fischer, J. Hennig and R. Leuschner, Time-resolved CIDNP in laser flash photolysis of aliphatic ketones. A quantitative analysis, Chem. Phys., 1985, 97(2-3), 217.

47 D. Neshchadin, F. Palumbo, M. S. Sinicropi, I. Andreu, G. Gescheidt and M. Miranda, Topological control in radical reactions of cholesterol in model dyads, Chem. Sci., 2013, 4(4), 1608.

48 I. Andreu, D. Neshchadin, S. N. Batchelor, M. A. Miranda and G. Gescheidt, Examples for biological reactivity involving free radicals followed by CIDNP, Mol. Phys., 2013, 111(18-19), 2992.

49 P. K. Das, M. V. Encinas, S. Steenken and J. C. Scaiano, Reaction of tert-butoxy radicals with phenols. Comparison with the reactions of carbon triplets, J. Am. Chem. Soc., 1981, 103(14), 4162.

50 M. V. Encinas and J. C. Scaiano, Reaction of Benzophznone triplets with allylic hydrogens. A laser flash photolysis study, J. Am. Chem. Soc., 1981, 103(21), 6393.

51 L. Hermosilla, J. M. G. de la Vega, C. Sieiro and P. Calle, DFT calculations of isotropic hyperfine couplking constants of nitrogen aromatic radicals: The challenge of nitroxide radicals, J. Chem. Theory Comput., 2011, 7(1), 169.

52 H. Kruse, L. Goerigk and S. W. Grimme, Why the standard B3LYP/6-31G* model chemistry should not be used in DFT calculations of molecular thermochemistry: Understanding and correcting the problem, J. Org. Chem., 2012, 77(23), 10824.

53 Y. Zhao and D. G. Truhlar, The M06 suite of density functional for main group thermochemistry, thermochemical kinetics, noncovalent interactions, excited states, and transition elements: Two new functional and systematic testing of four M06-class functional and 12 other functional, Theor. Chem. Acc., 2008, 120, 215.

54 J. W. Darcy, B. Koronkiewicz, G. A. Parada and J. M. Mayer, A continuum of proton-coupled electron transfer reactivity, Acc. Chem. Res., 2018, 51, 2391. 
55 M. J. Frisch, G. W. Trucks, H. B. Schlegel, G. E. Scuseria, M. A. Robb, J. R. Cheeseman, G. Scalmani, V. Barone, G. A. Petersson, H. Nakatsuji, X. Li, M. Caricato, A. V. Marenich, J. Bloino, B. G. Janesko, R. Gomperts, B. Mennucci, H. P. Hratchian, J. V. Ortiz, A. F. Izmaylov, J. L. Sonnenberg, D. Williams-Young, F. Ding, F. Lipparini, F. Egidi, B. Goings, B. Peng, A. Petrone, T. Henderson, D. Ranasinghe, V. G. Zakrzewski, J. Gao, N. Rega, G. Zheng, W. Liang, M. Hada, M. Ehara, K. Toyota, R. Fukuda, J. Hasegawa, M. Ishida, T. Nakajima, Y. Honda, O. Kitao, H. Nakai, T. Vreven, K. Throssell, J. A. Montgomery Jr., J. E. Peralta, F. Ogliaro, M. J. Bearpark, J. J. Heyd, E. N. Brothers, K. N. Kudin, V. N. Staroverov, T. A. Keith, R. Kobayashi, J. Normand, K. Raghavachari, A. P. Rendell, J. C. Burant, S. S. Iyengar, J. Tomasi, M. Cossi,
J. M. Millam, M. Klene, C. Adamo, R. Cammi, J. W. Ochterski, R. L. Martin, K. Morokuma, O. Farkas, J. B. Foresman and D. J. Fox, Gaussian 16, revision C.01, Gaussian, Inc., Wallingford, CT, 2016.

56 A. V. Marenich, C. J. Cramer and D. G. Truhlar, Universal solvation model based on solute electron density and on continuum model of the solvent defined by the bulk dielectric constant a,d atomic surface tensions, J. Phys. Chem. B, 2009, 113, 6378.

57 J. Ho, A. Klamt and M. L. Coote, Comments on the correct use of continuum solvent models, J. Phys. Chem. A, 2010, 114, 13442.

58 S. Marque, C. Le Mercier, P. Tordo and H. Fischer, Factors influencing the C-O-bond homolysis of trialkylhydroxylamines, Macromolecules, 2000, 33(12), 4403. 